\title{
Shocks vs Menu Costs: Patterns of Price Rigidity in an Estimated Multi-Sector Menu- Cost Model
}

\author{
Erwan Gautier ${ }^{1} \&$ Hervé Le Bihan ${ }^{2}$
}

May 2018, WP \#682

\begin{abstract}
Relying on a menu-cost model augmented with a time-dependent (Calvo) component, we investigate the structural sources of cross-sectoral heterogeneity in patterns of price setting. We use a large micro dataset of French consumer prices to estimate the model at the product level for 227 products. The Calvo component is found to be large in most sectors. Heterogeneity in structural parameters is also substantial. The combination of these two features leads to much larger real effects of monetary policy. The effect of monetary shock on output is more than 4 times larger than the one derived from a standard single-sector menu-cost model estimated using average moments.
\end{abstract}

Keywords: Price rigidity, menu cost, $(\mathrm{S}, \mathrm{s})$ models, adjustment cost, heterogeneity.

JEL classification: E31, D43, L11.

\footnotetext{
${ }^{1}$ Banque de France and Université de Nantes. erwan.gautier@banque-france.fr

${ }^{2}$ Banque de France herve.lebihan@banque-france.fr

This project benefited from earlier work with Nicolas Vincent. We are grateful to our discussants Oleksiy Kryvtsov (Banque de France seminar, 2017) and Ben Malin (Fed Cleveland Inflation conference, 2018) for their comments. We thank Fernando Alvarez, Christoph Grosse-Steffen, Michel Juillard, Pete Klenow, Francois Langot, Julien Matheron, Emi Nakamura, Ricardo Reis, Jón Steinsson and participants at the T2M annual conference (Lisbon, 2017), the EEA Congress (Lisbon, 2017), the OFCE-Sciences Po Workshop on Empirical Monetary Economics (Paris, 2017), the Fed of Cleveland Inflation Drivers and Dynamics Conference (Cleveland, 2018), and seminars at Curtin University (Perth, 2017), the Banque de France (2017), and Le Mans University (2018) for helpful discussions and advice. Views expressed in this paper do not necessarily represent those of the Banque de France.
}

Working Papers reflect the opinions of the authors and do not necessarily express the views of the Banque de France. This document is available on publications.banque-france.fr/en 


\section{NON-TECHNICAL SUMMARY}

A voluminous literature has described patterns of price adjustments both in the United States and the euro area. Two salient features of the micro price dynamics are often reported. First, prices are quite rigid since the frequency of price changes is small (especially when sales-related price changes are disregarded). Second, cross-sectoral heterogeneity is pervasive: price changes are for instance quite frequent in energy but rather rare in services. A still open question is to what extent these patterns of price rigidity reflect underlying features of pricing frictions or characteristics of the shocks hitting the different sectors. This paper provides new evidence on the empirical relevance of pricing frictions frequently used in macro models and on the origins of cross-sectoral heterogeneity in price rigidity. We also derive macro implications of our results for the real effects of monetary policy.

To address this issue, we rely on a structural multi-sector menu cost model, which nests the standard menu cost model and the Calvo model of "exogenous" price rigidity. Using this model, and a minimum distance estimation procedure, we estimate the value of the menu cost, the Calvo component (the probability of drawing a free opportunity to change prices), and the parameters characterizing the variance and persistence of sectoral productivity shock process at the product level. We estimate this model for more than 200 different products of the French CPI. Empirical moments are obtained using a large microeconomic data set of more than 25 million of individual consumer price quotes. The general equilibrium set-up used allows us to simulate the response of the economy to a monetary shock, and assess the degree of the monetary non-neutrality. We compare the aggregate response for different estimations of parameters of the model (one sector vs. multi-sector, augmented menu cost model vs Calvo or pure menu cost model) and we also compare the impulse response functions obtained for France and the US economy.

\section{Impulse Response of Output to a Nominal Shock - Single-Sector Models vs Multi- Sector Models}

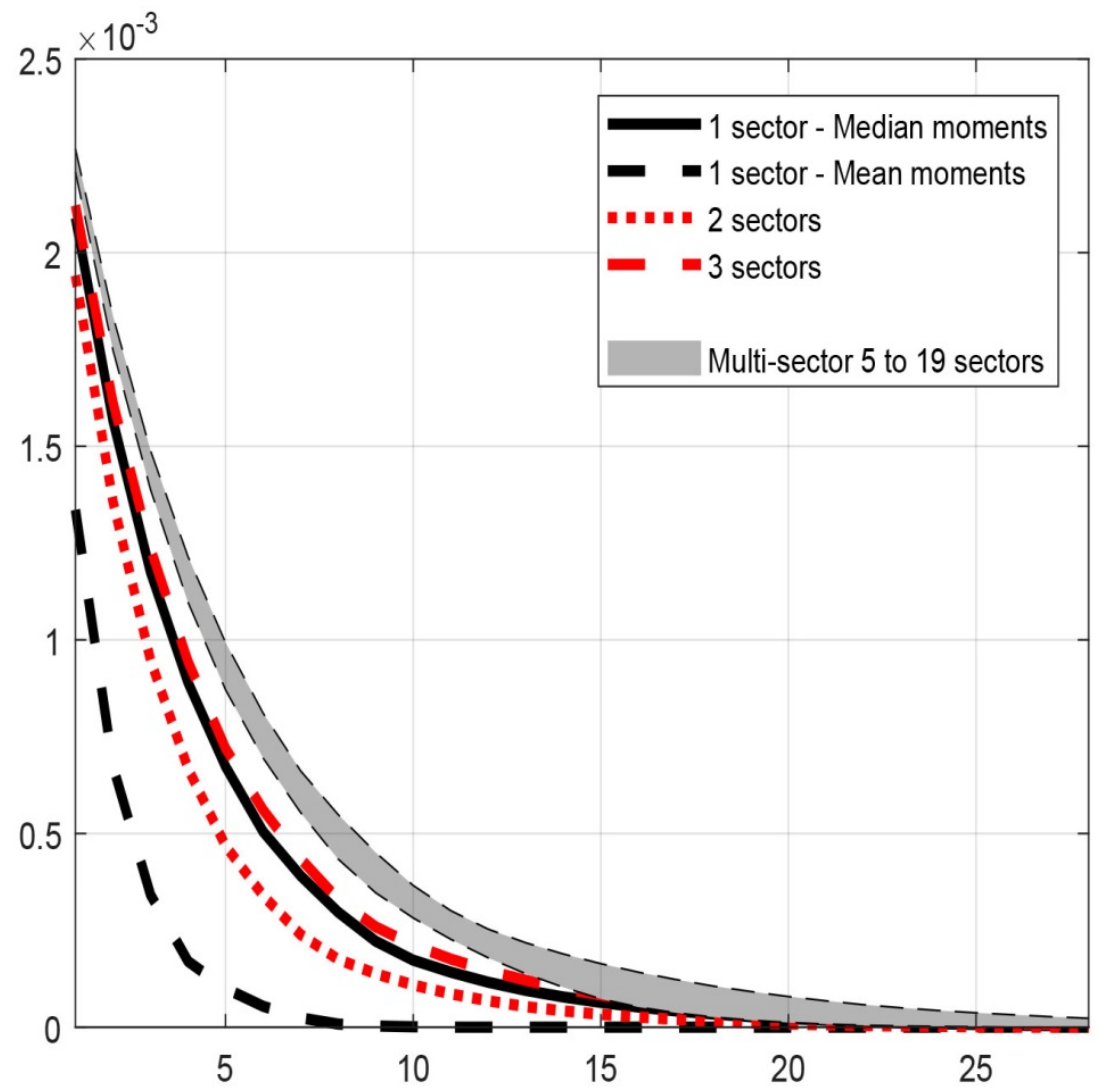

Note: Aggregate responses of output to a monetary policy shock of one standard deviation of inflation $(0.3 \%)$ obtained from different models. One sector model fitting average moments (dark dashed line), one sector model fitting the median moments of the data (dark solid line), two--sector model (energy and core sectors) (red dotted line), three-sector model (non-energy goods, energy, services) (red dashed line), multi-sector models where sectors group products according to the value of the Calvo component (grey shaded area -5 to 19 sectors). 
Our main results are the following:

i) There is a substantial degree of heterogeneity across sectors in all structural parameters.

ii) The Calvo component plays a crucial role to fit the data and is the main source of price rigidity. The genuine "menu cost" component contributes only partially to the overall degree of price rigidity. Across sectors, the heterogeneity in the Calvo component (as opposed to heterogeneity in cost shocks) explains most of the heterogeneity in the frequency of price changes across products.

iii) Product heterogeneity matters for monetary policy: the degree of monetary non neutrality is much larger in a multi-sector model than in a one-sector model calibrated on the same average moments. However, a single-sector model estimated using median moments is able to generate the same degree of non-neutrality than multi-sector models.

iv) A 3-sector model (energy, services and manufacturing goods) is able to generate the same degree of monetary non-neutrality as a multi-sector model with much more products. Our results also suggest that the amplification of non-neutrality due to product heterogeneity is mostly coming from heterogeneity in the Calvo component.

v) Using models estimated on comparable US and French price moments and assuming that aggregate parameters (i.e. parameters other than the ones related to productivity and price-setting frictions) are identical in both economies, the degrees of monetary non-neutrality are quite similar in both economies.

\title{
Chocs versus « coûts de menu » : caractériser la rigidité des prix à l'aide d'un modèle de coût de menu multisectoriel
}

\begin{abstract}
RÉSUMÉ
Nous développons un modèle structurel de fixation des prix de type « coûts de menu » complété par une composante dépendante du temps (de type Calvo), pour analyser les sources et l'hétérogénéité sectorielle de la rigidité des prix. Nous estimons le modèle au niveau produit pour 227 produits, en utilisant une vaste base de données microéconomiques des prix à la consommation français. Les résultats indiquent que dans la plupart des secteurs, la composante «dépendante au temps » est significative; et que l'hétérogénéité des paramètres structurels est substantielle. La combinaison de ces deux caractéristiques se traduit par des effets réels de la politique monétaire plus importants. L'effet d'un choc monétaire sur la production est plus de quatre fois plus important que celui obtenu à partir d'un modèle de coût de menu standard à un secteur estimé à partir des moments moyens.

Mots-clés : rigidité des prix, coût de menu, coûts d'ajustement, hétérogénéité sectorielle.

Les Documents de travail reflètent les idées personnelles de leurs auteurs et n'expriment pas nécessairement la position de la Banque de France. Ils sont disponibles sur publications.banque-france.fr
\end{abstract}




\section{Introduction}

Patterns of price adjustments both in the United States and the euro area have been described in a voluminous literature 11 Two salient features of the micro price dynamics are often reported. First, prices are quite rigid since the frequency of price changes is small (especially when salesrelated price changes are disregarded). Second, cross-sectoral heterogeneity is pervasive: price changes are for instance quite frequent in energy but rather rare in services. A still open question is to what extent these patterns of price rigidity reflect underlying specific features of pricing frictions or characteristics of the shocks hitting the different sectors. By estimating a structural menu-cost model with micro price data, we provide in this paper new evidence on the empirical relevance of pricing frictions frequently used in macro models and on the origins of cross-sectoral heterogeneity in price rigidity. We also derive macro implications of our results for the real effects of monetary policy.

Our empirical analysis relies on a structural multi-sector menu cost model, which nests the standard menu cost model and the Calvo model of "exogenous" price rigidity - a set-up close to the CalvoPlus model of Nakamura and Steinsson (2010). We estimate this model at the product level and through a minimum distance estimation procedure. Doing so, we deliver new product-level estimates of the menu cost, the Calvo probability (i.e. the probability of drawing a free opportunity to change prices), and the variance and persistence of idiosyncratic productivity shocks. A large microeconomic data set of more than 25 million of individual consumer price quotes in France allows us to compute moments which are then used to estimate the model for more than 200 different products of the CPI. In this general equilibrium set-up, we finally simulate the response of the economy to a monetary shock, and assess the degree of monetary non-neutrality. We compare the aggregate response for different versions of the model (one-sector vs. multi-sector, augmented menu cost model vs Calvo or standard fixed menu-cost models) and we also compare the impulse response functions obtained for France and the US

\footnotetext{
${ }^{1}$ Recent surveys include Klenow and Malin (2010) and Nakamura and Steinsson (2013).
} 
economy.

Our main results are the following. First, there is a substantial degree of heterogeneity across sectors in all structural parameters. The relative dispersion in parameter estimates across products is however much more important for parameters driving pricing frictions. Second, the Calvo component plays a crucial role to fit the data and is the main source of price rigidity. The genuine "menu cost" component contributes only partially to the overall degree of price rigidity. Across sectors, the heterogeneity in the Calvo component (as opposition to heterogeneity in cost shocks) explains most of the heterogeneity in the frequency of price changes. Third, product heterogeneity matters for monetary policy: the degree of monetary non neutrality is much larger in a multi-sector model than in a one-sector model calibrated on the same average moments. However, a single-sector model estimated using median moments is able to generate the same degree of non-neutrality than multi-sector models. Besides, we find that a 3 -sector model (energy, services and manufacturing goods) is able to generate the same degree of monetary non-neutrality than a multi-sector model with much more products (10 or more). Our results also suggest that the amplification of non-neutrality due to product heterogeneity is mostly coming from heterogeneity in the Calvo component. Fourth, using models estimated on comparable US and French price moments and assuming that aggregate parameters (i.e. parameters other than the ones related to productivity and price-setting frictions) are identical in both economies, we find that the degrees of monetary non-neutrality are quite similar in both economies ${ }^{2}$

Our results build on a large literature that has provided new theoretical and empirical results on price rigidity and we contribute to this literature along several dimensions.

\footnotetext{
${ }^{2}$ One restriction of this comparison is that we exclude sales from our analysis. Sales are much less prevalent in France than in the US. Whether sales are significantly adding to price flexibility in the case of the US is the topic of a substantial controversy, see e.g. Kryvtsov and Vincent (2014), Gagnon, Lopez-Salido, and Sockin (2015), Coibion, Gorodnichenko, and Hong (2015), Anderson, Malin, Nakamura, Simester, and Steinsson (2017). Our analysis takes no stand on this issue. In a study taking on board price changes due to sales, Alvarez and Burriel (2010) use a time-dependent generalized Calvo with heterogeneous sectors calibrated to fit the distribution of price durations in both Euro area and the United States. They find that monetary non-neutrality is larger in Europe than in the United States.
} 
First, we add to the literature relying on cross-sectoral heterogeneity of price rigidity indicators to assess models of price rigidity. Ample descriptive evidence has been accumulated on the large sectoral heterogeneity of apparent price rigidity (Bils and Klenow (2004) on the United States, Dhyne, Alvarez, Bihan, Veronese, Dias, Hoffmann, Jonker, Lunnemann, Rumler, and Vilmunen (2006), Baudry, Le Bihan, Sevestre, and Tarrieu (2007), on the euro area and France). Some microeconometric contributions Dhyne, Fuss, Pesaran, and Sevestre 2011) or Fougere, Le Bihan, and Sevestre (2007) have related this sectoral heterogeneity to theoretical predictions of price rigidity models. We here provide a structural interpretation to this cross-product heterogeneity. We find that there is a substantial degree of heterogeneity in structural parameters across sectors. Besides, heterogeneity in pricing frictions is more important than heterogeneity in productivity shocks to replicate stylized facts on consumer price adjustments. One contribution is here to provide structural estimates of price rigidity for a large European economy and to compare them to the ones obtained for the United States. To our knowledge, such structural menu cost models have not been previously estimated on micro data for a euro-area economy. Previous studies on European economies include Karadi and Reiff (2014) and Carlsson (2017) who estimate parameters of menu-cost models respectively using food CPI Hungarian data and on Swedish producer price data ${ }^{3}$ Moreover, we here cover a large number of CPI sectors including services, whereas most macro models are calibrated using micro data for some specific sectors or using grocery price data (Nakamura and Steinsson (2010) being a prominent exception). In our augmented menu-cost framework, we find that, excluding sales from the analysis, costs of price adjustment are a little larger in the United States than in France, whereas productivity shocks have a larger variance in the United States than in France.

A second contribution is to estimate in a single set-up the relative importance of time-dependent (Calvo) and state-dependent (menu cost) pricing frictions to replicate patterns of price rigidity. This contribution builds on the recent literature featuring random menu-cost models which en-

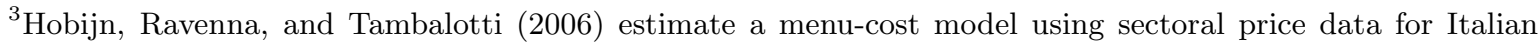
restaurants.
} 
compass the Calvo and menu-cost model, including Nakamura and Steinsson (2010) and Alvarez, Le Bihan, and Lippi (2016) (see also Luo and Villar (2015) and Blanco (2017) for papers using a similar set-up) $4_{4}^{4}$ This literature has shown that the degree of monetary policy non-neutrality is larger when assuming a random menu cost than in the "standard" fixed menu cost model of Golosov and Lucas (2007) 5 Our contribution is here to provide an estimation of the relative contributions to price rigidity of the Calvo and the menu-cost components. In this respect we relax an assumption of Nakamura and Steinsson (2010) who set the probability of being in the low menu cost regime to be equal to the frequency of price changes. Our approach is also complementary to the sufficient statistics approach of Alvarez, Le Bihan, and Lippi (2016) ${ }^{6}$ We find that the Calvo component has a sizeable contribution to price rigidity observed in the data. The "time dependent" motive for price changes is estimated to generate about $70 \%$ of all price changes in our baseline model. In addition, across sectors, the heterogeneity in the Calvo component (as opposition to heterogeneity in cost shocks) is found to explain most of the heterogeneity in the frequency of price changes. With some qualifications, our results provide some support to the literature that has studied inflation dynamics relying on multi-sector Calvo models featuring heterogeneity in the Calvo parameter (see for instance, Bils and Klenow (2004), Carvalho (2006), Eusepi, Hobijn, and Tambalotti (2011), Le Bihan and Matheron (2012), and Dixon and Tian (2017) for models calibrated with CPI micro data, Pasten, Schoenle, and Weber (2017) for a multisector calibrated to PPI data, or Bouakez, Cardia, and Ruge-Murcia (2009) who estimate a model based on sectoral aggregate data).

Our third contribution is to assess, in a single set-up, the degree of amplification of monetary pol-

\footnotetext{
${ }^{4}$ Early models with random cost of adjustment have been introduced by Caballero and Engel (1999) and Dotsey, King, and Wolman (1999).

5Another recent strand of literature has proposed alternative mechanisms to rationalize small price changes and monetary non neutrality, these mechanisms consist of multi-product firms (Midrigan (2011)), strategic complementarities (Burstein and Hellwig (2006)), information capacity constraint (Woodford(2009)) or errors in price revisions (Costain and Nakov (2011, 2012)). In these papers, the decision rule is observationally equivalent to that derived under a random menu-cost model.

${ }^{6}$ One difference with this latter paper is that we do not rely on zero trend inflation, or Brownian motion cost shock approximations (used to derive analytical solutions) - but we have to rely on numerical techniques and a simulation approach.
} 
icy non-neutrality brought along by the Calvo component, and by heterogeneity in price-setting. This follows prominent contributions by Carvalho (2006) and Nakamura and Steinsson (2010) who mainly focus on amplification effect resulting from sectoral heterogeneity and by Midrigan (2011) and Alvarez, Le Bihan, and Lippi (2016) who focus on amplification effect resulting from the assumption of random menu cost and/or multiproduct firms.7.$^{7}$ Cross-product heterogeneity matters: we find that the degree of monetary non-neutrality is about 4 times larger in a model with 3 or more different sectors than in a single sector model calibrated on the same average moments. We also show that a model with only 3 sectors (energy, services and manufacturing products) is able to generate almost the same degree of monetary non-neutrality than a model with 4 or more different sectors. This result is in line with Carvalho and Nechio (2017). The Calvo component also matters: the real effect of monetary policy is around twice as large as the real effects obtained using a fixed menu-cost model a la Golosov and Lucas (2007) (based on approximate models of the full multi sector economy).

Our paper is structured as follows. Section 2 reviews the micro data as well as the main facts our model seeks to explain. Section 3 presents the augmented menu cost model we use, as well as its main properties, allowing to illustrate how data moments identify the parameters. Section 4 provides evidence on the structural parameters, and investigates to what extent heterogeneity in price stickiness is driven by the properties of the shock processes, or the heterogeneity in menu costs. Section 5 examines the aggregate real response of the economy to a monetary policy shock and compares the results for different set-ups of the models and also compares results obtained for France and the US economy. Section 6 concludes.

\section{Data and Micro Facts}

We first present stylized facts on the cross-sectoral heterogeneity of usual price rigidity indicators (i.e. mainly the frequency and the size of price adjustments) in France.

\footnotetext{
${ }^{7}$ See also Carvalho and Kryvtsov (2018) for a multi-sector menu-cost model matching cross-product heterogeneity in price selection and small degree of price selection at the aggregate level.
} 


\subsection{Data}

We here rely on longitudinal data sets of monthly price quotes collected by the Institut National de la Statistique et des Études Économiques (INSEE) to compute the monthly French CPI. We have stacked data sets used in Baudry et al. (2007), Berardi, Gautier, and Le Bihan (2015) and Berardi and Gautier (2016) to obtain a long sample covering a period of about 20 years between August 1994 and May 2014 7 The data set contains more than 25 million price quotes and covers a little less than $65 \%$ of the CPI weights ${ }^{9}$ On average, the sample contains between 120,000 and 130,000 individual price quotes each month, collected from over 20,000 different retailers for several thousands different products and services.

To compute price rigidity indicators, we have first dropped data collected around VAT changes (i.e. in Aug. and Sept. 1995, Sept. Oct. 1999, April and May 2000, July-Sept. 2009, Jan-Feb. 2012 and Jan-Feb. 2014) and before and after the euro cash changeover (between Aug 2001 and June 2002). We have also dropped outliers which are defined as price changes involving upward or downward changes by a factor larger than 5, and trimmed them from the data, we have also removed all out-of-season items from our data set. We have also dropped price changes smaller than $1 \%$ in absolute values in order to control for possible small price changes due to measurement errors (Eichenbaum, Jaimovich, Rebelo, and Smith (2014)).

Our price rigidity indicators are computed excluding seasonal sales and promotions relying a flag variable that identifies whether a price corresponds to a sale price, either in the form of seasonal sales or temporary promotional discounts. Berardi, Gautier, and Le Bihan (2015) find that in France price changes due to sales are less responsive to economic shocks than regular prices. Moreover, sales and promotions are mostly concentrated in some sectors (i.e. clothing and shoes, and furnishings). Our model is not able to reproduce price changes due to sales. In particular, we exclude clothing from our analysis since price adjustment patterns in this

\footnotetext{
${ }^{8}$ French micro price data are presented with much more details in these papers.

${ }^{9}$ Some categories of goods and services are not available in our sample: centrally collected prices, among which car prices and administered prices (e.g. tobacco) or public utility prices (e.g. electricity), as well as other types of products such as fresh food or rents.
} 
sector are essentially driven by sales and are difficult to replicate using a standard menu cost framework.

Finally, our aim is also to compare price rigidity in France and in the United States. To perform this comparison, we rely on moments computed by Nakamura and Steinsson $(2008)$ for disaggregated US products and released in their web appendix (Nakamura and Steinsson (2008)). We also use a bridge table to match the European CPI classification (COICOP) and the US one (ELI) (see Berardi, Gautier, and Le Bihan (2015) for details) 10 Overall, we are able to match 206 French products (over a total of 227 products) with corresponding US products (i.e. more than $54 \%$ of the French CPI). The main products excluded from the US data set consist of cars, electricity and gas, medical services, airline fare, telephone services and fresh food ${ }^{11}$ Those products are typically associated with rather high frequencies of price changes (for the United States, the average frequency of regular price changes for those products is higher than $30 \%$ ). To perform an accurate comparison, we rely on moments calculated excluding sales. As mentioned earlier, this is a potential limitation of the comparison since sales are much more frequent in the United States than in France.

\subsection{Facts}

We here briefly review the main stylized facts from the micro data. For that, we compute the standard price rigidity statistics at a disaggregated level (the 5-digit level of the COICOP classification): the frequency of price changes, the share of price increases among price changes, the median of absolute price changes, the interquartile range and the kurtosis of price change distribution. We obtain such statistics for 227 products and services. Table 1 reports simple weighted statistics both at the aggregate level, and for five broad sectors: Food, Manufacturing goods (split into Durables and Other goods), Energy and Services. The main stylized facts are the following. Price changes are infrequent: the weighted median frequency of price changes over

\footnotetext{
${ }^{10}$ The bridge table is available at https://sites.google.com/site/erwangautiereconomics/research .

${ }^{11}$ INSEE did not include in the data set available to us the set of prices that are mainly collected at the national level rather than in retail outlets, which match this list of items.
} 
all 227 products is $8.4 \%$ per month. Price decreases are not rare: about $70 \%$ of price changes are price increases. Price changes are rather sizeable: the median size of price changes is about $5 \%$, but large and small price changes are not rare leading to a high interquartile range of $7 \%$ and a median kurtosis of about 4.5 .

Another important salient feature of the data is the large degree of heterogeneity across products. Price are more frequent for energy and food products ( $75 \%$ for energy and about $15 \%$ for food) whereas they are quite rare for services or durables (about 5\%) (Table 1). Figure 1 plots the distribution of product specific frequencies of price changes and proportions of price increases. About one half of the products have a frequency of price changes of less than $5 \%$, whereas the frequency of price changes is larger than $10 \%$ for more than one third of products. Turning to the share of price increases among price changes, in some sectors (mostly services) it is above $80 \%$. Figure 2 plots the distribution of the moments related to the distribution of price changes across products. Here again, there is a pervasive degree of sectoral heterogeneity.

A further important finding is that the degree of cross-product heterogeneity is broadly similar for France and for the United States. Table 2 compares, with a fairly high degree of precision, price adjustment patterns for similar French and US products. The frequency of price changes in the United States is only slightly higher than in France. As already underlined by Berardi, Gautier, and Le Bihan (2015) the main difference comes from a higher share of sales in the United States. The share of price increases is also very similar. The main difference between the two countries concerns the size of price adjustments: regular price adjustments are about twice larger in the United States than in France.

\section{A Multi-Sector Menu Cost Model}

To understand the sources and consequences of cross-sectoral heterogeneity in price rigidity, we set up a multi-sector menu-cost model, building on Nakamura and Steinsson (2010). The model features heterogeneity in price rigidity structural parameters and in sectoral shock processes. 


\subsection{Model}

\subsubsection{Household behavior}

The representative household maximizes an intertemporal utility function given by:

$$
E_{t} \sum_{\tau=0}^{\infty} \beta^{\tau}\left[\frac{1}{1-\gamma} C_{t+\tau}^{1-\gamma}-\omega L_{t+\tau}\right]
$$

where the disutility of labor is linear, $L_{t}$ is Labor, $C_{t}$ is a consumption aggregate, $\beta$ is a discount factor, $\gamma$ the intertemporal elasticity of substitution, $\omega$ a labor disutility parameter.

Aggregate consumption $C_{t}$ is given by an aggregation of goods produced in different sectors. There are $K$ sectors in the economy. A continuum of firms indexed by $i$ operates in each sector $k$, and produce differentiated products. The level of the aggregate composite good $C_{t}$ is given by a Dixit-Stiglitz index of the differentiated goods produced by the $K$ different sectors: $C_{t}=\left[\sum_{k=1}^{K} \omega_{k}^{\frac{1}{\theta}} C_{k, t}^{\frac{\theta-1}{\theta}}\right]^{\frac{\theta}{\theta-1}}$. In the latter expression, the level of consumption of the good produced by the sector $k$ is given by: $C_{k, t}=\omega_{k}\left[\int_{0}^{1} C_{i, k, t}^{\frac{\theta-1}{\theta}} d i\right]^{\frac{\theta}{\theta-1}}$ where $\theta$ is the elasticity of substitution between the different goods (which is assumed to be identical within a sector and across sectors), and $\omega_{k}$ is a sectoral weight that in the empirical application will be set equal to the CPI weight of product $k$ in the CPI.

The maximization program of the households is subject to a budget constraint:

$$
P_{t} C_{t}+E_{t}\left[Q_{t, t+1} B_{t+1}\right] \leq B_{t}+W_{t} L_{t}+\text { Others }
$$

where "Others" include dividends and the proceeds of a complete set of Arrow Debreu securities, $W_{t}$ is nominal wage, $B_{t}$ is the quantity of riskless one-period bonds maturing at date $t+1$ held by the household, $Q_{t, t+1}$ is the stochastic discount factor (the expectation of which is the price of the bond).

From the first-order conditions, in each state of the world, the stochastic discount factor is 
given by:

$$
Q_{t, t+1}=\beta\left(\frac{C_{t+1}}{C_{t}}\right)^{-\gamma}\left(\frac{P_{t}}{P_{t+1}}\right)
$$

The price of goods produced by firm $i$ operating in sector $k$ will be denoted $P_{i, k, t}$.

Demand addressed to the firm $i$, resulting from optimal allocation across goods is the following:

$$
C_{i, k, t}^{d}=C_{t}\left(\frac{P_{i, k, t}}{P_{t}}\right)^{-\theta}
$$

Finally, first-order condition also determine the real wage, given by:

$$
\frac{W_{t}}{P_{t}}=\omega C_{t}^{\gamma}
$$

\subsubsection{Firms}

We consider the pricing decision of a firm that operates in a monopolistic competition environment à la Dixit-Stiglitz.

The production function of firm $i$ in sector $k$ is linear and given by:

$$
Y_{i, k, t}=A_{i, k, t} N_{i, k, t}
$$

where $A_{i, k, t}$ is idiosyncratic productivity and $N_{i, k, t}$ hours worked. Output is $Y_{i, k, t}$, and in the baseline version of the model output equals consumption.

The law of motion for productivity is an auto-regressive process, with parameters that are identical within a sector:

$$
\ln A_{i, k, t}=\rho_{k} \ln A_{i, k, t-1}+\varepsilon_{i, k, t}
$$

where $\varepsilon_{i, k, t}$ is a i.i.d Gaussian idiosyncratic shock with variance $\sigma_{k}^{2}=E \varepsilon_{i, k, t}^{2}$. Persistence parameters $\rho_{k}$, and the volatility parameters $\sigma_{k}^{2}$ are parameters of interest that vary across sectors.

A recent literature has relied on alternative processes for productivity shocks. In particular, Midrigan (2011) and Karadi and Reiff (2014) have used cost processes featuring a Poisson 
component, resulting in leptokurtik cost shocks. This is an alternative mechanism to generate the fat-tailed distributions of price changes (as observed in the data). We do not allow for such a process in our baseline version of the model for two reasons. First, there is an identification issue, which makes it difficult to disentangle this mechanism, from the Calvo type of price friction. Second, the assumption of fat-tailed shocks is debatable when actual price changes are rare since the cost shock will be the accumulation of cost shocks over a large period of time (see Alvarez, Le Bihan, and Lippi (2016)).

The aggregate price level is given by: $P_{t}=\left[\sum_{k=1}^{K} \omega_{k} P_{k, t}^{1-\theta}\right]^{\frac{1}{1-\theta}}$ The sectoral price level is given by: $P_{k, t}=\left[\int_{0}^{1} P_{i, k, t}^{1-\theta} d i\right]^{\frac{1}{1-\theta}}$

The per-period real profit function is then:

$$
\Pi_{i, k, t}=\frac{P_{i, k, t}}{P_{t}} C_{t}\left(\frac{P_{i, k, t}}{P_{t}}\right)^{-\theta}-\left(\frac{W_{t}}{P_{t}}\right) \frac{C_{i, k, t}}{A_{i, k, t}}
$$

In addition, price adjustment is costly: when changing prices, a menu cost is incurred. The menu cost $c_{i, k, t} W_{t}$ is assumed to be time-varying. This allow us to handle a shortcoming of "first-generation" menu-cost emphasized by emphasized by Klenow and Kryvtsov (2008) and a number of subsequent contributions: model with fixed menu costs are typically not able to fit frequent small price changes observed in most data sets. With a probability $\lambda_{k}$, the price change is free: $c_{i, k, t}=0$; with a probability $1-\lambda_{k}, c_{i, k, t}=\mu_{k}$. Thus $\mu_{k}$ is the cost paid by the firm conditional on drawing a non-zero menu cost.

The model is close to Nakamura and Steinsson (2010)'s "CalvoPlus" model. It encompasses both the pure menu cost model (corresponding to $\lambda_{k}=0$ ) and the Calvo model (corresponding to $\left.\mu_{k}=\infty\right)$, in which price changes are triggered only by free adjustment opportunities. Sectorspecific price rigidity parameters of interest are: $\mu_{k}$ and $\lambda_{k}$.

For a firm $i$ belonging to sector $k$, we denote the vector of state variables: $\mathcal{S}_{i, t}=\left\{P_{i, t-1} / P_{t}, A_{i, t}\right\}$. 
The present value of profits is:

$$
V\left(\mathcal{S}_{i, t}\right)=\max \left[V^{n c}\left(\mathcal{S}_{i, t}\right), V^{c}\left(\mathcal{S}_{i, t}\right)\right]
$$

where $V^{c}$ is the value when price adjusts:

$$
V^{c}\left(\mathcal{S}_{i, t}\right)=\max _{P_{i, t}}\left[\Pi\left(P_{i, t} / P_{t}, A_{i, t}\right)+E_{t} Q_{t+1} V\left(\mathcal{S}_{i, t+1}\right)\right]-c_{i, t} \frac{W_{t}}{P_{t}}
$$

and $V^{n c}$ is value when price do not adjust.

$$
V^{n c}\left(\mathcal{S}_{t}\right)=\Pi\left(P_{i, t-1} / P_{t}, A_{i, t}\right)+E_{t} Q_{t+1} V\left(\mathcal{S}_{i, t+1}\right)
$$

The model is solved by numerical methods and value function iteration. As it is common in the menu cost set-up, the solution will give rise to a "range of inaction", rationalizing infrequent price changes.

\subsection{Solution of the model and equilibrium}

To close the model, we assume the monetary authority targets a path for nominal value added: $S_{t}=P_{t} C_{t}$. Nominal output $S_{t}$ follows a random walk with drift:

$$
\log \left(S_{t}\right)=\pi+\log \left(S_{t-1}\right)+\eta_{t}
$$

where $\pi$ is trend inflation and $\eta_{t}$ is an aggregate policy shock.

The firm program is solved by value-function iteration. A sketch of the approach is as follows. Given $S_{t}$ and $P_{t}$ - where, for exposition purpose, the process for $P_{t}$ is temporarily assumed to be known- real aggregate consumption $C_{t}$ derives from the nominal value added identity. For a representative firm in sector $k$, facing a given set of parameters $\Omega_{k}=\left(\lambda_{k}, \mu_{k}, \sigma_{k}, \rho_{k}\right)$, the processes for productivity, menu costs, and aggregate inflation are discretized on a grid. We 
assume an initial set of values characterizing function $V($.$) on the grid. We then solve the firm's$ program to derive the policy function and a resulting new value function using equations (3), (4), (5). Iterations on function $V($.$) are carried out until convergence. Upon convergence, the$ resulting policy function is used to simulate the model and produce simulated statistics on the distribution of price changes.

In general equilibrium, one needs to acknowledge that $P_{t}$ is endogenous. The firm's problem becomes infinite-dimensional since $P_{t}$ is the aggregation of all individual prices. Following Krusell and Smith (1998) and the implementation of their procedure by Nakamura and Steinsson (2010), we assume that firms perceive the evolution of the price level as a function of a small number of moments of the price distribution, namely:

$$
\frac{P_{t}}{P_{t-1}}=\Gamma\left(\frac{S_{t}}{P_{t-1}}\right)
$$

The computation of the general equilibrium is performed as follows. The above iteration is carried out to find the policy function. Note that the state variables include now $P_{i, t-1} / P_{t}, A_{i, t}$ but also $S_{t} / P_{t}$. The aggregate price change is then computed, and compared with predictions from (6). Function $\Gamma$ is then updated, and we iterate over $\Gamma$ and value-function iteration loops until convergence. Upon convergence function, the perceived aggregate law of motion $\Gamma$ is consistent with individual policy rules.

Following Nakamura and Steinsson (2010), and for robustness purposes, we also consider a model with intermediate inputs (see the Appendix for the specification in that case). Introducing such an ingredient allows us to consider strategic complementarities in the model since firms buying intermediate inputs from other firms take into account prices of other firms to set their own price. 


\subsection{Predefined parameters}

In our exercize, only parameters corresponding to pricing frictions and idiosyncratic productivity shocks are estimated. The other parameters of the model have been calibrated prior to the estimation. Following Nakamura and Steinsson (2008), we assume $\gamma=1$ (that is, log utility), and set the discount factor to $\beta=0.96^{1 / 12}$, and the elasticity of demand to $\theta=4$. These values fall in standard ranges, and the latter is consistent with a mark-up of 1.33. We also impose the parameters associated with the aggregate nominal growth process. Note that there is no real growth in the model, so we use inflation rather than nominal GDP growth to calibrate parameters. The mean of the process for overall monthly inflation is set to $\pi=0.125 \%$ and the standard deviation of $\eta_{t}^{P}$ to $\sigma_{\eta}=0.28 \%$ from the aggregate French CPI data over our sample period. In the model where we allow intermediate inputs, we calibrate the share of inputs to 0.7. This value, chosen to be identical to that in Nakamura and Steinsson (2010), is close to the value we calculated using National Accounts time series for France. Over the period 19942014 , the average share of intermediate inputs is equal to $50 \%$ of total production. The cost share of intermediate inputs is equal to the revenue share (0.5) times the markup $\left(\frac{\theta}{\theta-1}=4 / 3\right)$, which leads a weighted average cost share of intermediate inputs close to $70 \%$ (see Table A in Appendix). This figure is larger when considering only manufacturing industry $\left(s_{m}=0.8\right.$ to $0.9)$.

\subsection{Model Properties}

To illustrate the properties of our model and investigate how moments can help to identify structural parameters, we investigate how the simulated moments generated from the theoretical model vary with each of the 4 parameters of interest. Results are reported in Figure 3 and Figure 4. Two general comments can be made. First, moments do vary with parameters, which provides comfort as regards identification. Second, none of the parameters is pinned down by a single moment, which motivates our use of a SMM estimation technique. 
Looking now at parameters in more details, a higher $\lambda$ - the probability of a free menu cost (top panel of Figure 3) - is associated with a larger frequency of price changes. It also results in a lower median absolute price changes, consistently with the literature pointing that the Calvo component is needed to generate small price changes and a larger kurtosis (see for instance Alvarez, Le Bihan, and Lippi (2016)). In our set-up with positive inflation, a larger $\lambda$ is also associated with a higher probability of price decreases since the future possibility of free price change opportunity attenuates the firms' reluctance to cut prices today. In addition, more frequent opportunities of free price changes result in more dispersed price changes, and so in a larger interquartile range of price changes.

As predicted by a standard menu-cost model, a larger menu cost $\mu$ lowers the frequency of price changes (bottom panel of Figure 3). The share of price increases is also rising with the menu cost size since firms with higher menu costs are more likely to react to trend inflation than to productivity shocks (which trigger most of the price decreases). In contrast with standard predictions of a menu-cost model like Sheshinski and Weiss (1977), the median absolute price changes is decreasing with the size of menu cost. This result is due to the presence of rather large productivity shocks. A larger menu cost provides less incentives for firms to react to productivity shocks, and the share of price decreases declines as well as the median size (reflecting that price increases have on average a smaller absolute size than price decrease). The interquartile range is smaller also because of the lower share of price decreases.

Finally, increasing either the standard deviation of the innovation of productivity shock $\sigma_{k}$ or its persistence $\rho_{k}$ (Figure 4), gives rise to a larger frequency of price changes, to a larger share of price decreases, and to larger and more variable prices changes. However, the kurtosis of price changes decreases when shock volatility increases, as the model is then closer to a flexible price set-up and the distribution of price changes looks more like the (Gaussian) distribution of shocks. 


\section{Empirical Results}

This section presents our estimation results. Using a simulated moment method (SMM) technique, we estimate parameters associated with both the menu cost and the productivity process and we consider one-sector and multi-sector versions of the model.

\subsection{Estimation approach}

Estimated parameters include four parameters for each sector: the probability of drawing a free adjustment cost $\lambda$, the menu cost $\mu$ and two parameters for the productivity process: the innovation standard deviation $\sigma$ and persistence $\rho{ }^{12}$ To estimate parameters, we rely on an SMM technique which consists of finding parameter values that minimize the distance between actual moments calculated from the data and the simulated moments generated from our model. We proceed as follows. A vector of moments $m$ is selected and computed from the actual micro CPI price data. For a given candidate set of parameters $\Omega$, we solve the policy function, we simulate large price trajectories from the model, and compute the simulated moments $\hat{m}(\Omega)$. For each set of parameters $\Omega$, we can calculate the difference between actual moments and simulated moments, which gives the vector $m-\hat{m}(\Omega)$. The SMM estimation technique consists of finding the set of parameters $\hat{\Omega}$ that minimizes the weighted difference between the actual and simulated moments:

$$
\hat{\Omega}=\operatorname{argmin}_{\Omega}\left[(m-\hat{m}(\Omega))^{\prime} W(m-\hat{m}(\Omega))\right]
$$

where the weighting matrix $W$ is here chosen as the inverse of variance of the data moments (obtained using bootstrap simulations run at the product level (100 different samples of observations have been drawn for each product)). Minimization is performed using a numerical routine 13

\footnotetext{
${ }^{12}$ We drop index $k$ to alleviate notations.

${ }^{13}$ As it is not uncommon in work with large micro datasets (e.g. Acemoglu, Akcigit, Hanley, and Kerr (2016)), we do not report standard errors of SMM parameters since, given the huge size of the data set and the resulting
} 
Our implementation of the SMM uses 5 moments as targets: the frequency of price changes, the proportion of price increases among price changes, the median absolute price change, the interquartile range and the kurtosis of the distribution of price changes. Table 3 compares actual and simulated moments obtained from our estimated parameters. These moments have been outlined in the literature as relevant for identifying menu cost, as well as the relative importance of the state-dependent and time-dependent components of price changes, properties which were confirmed in the previous section ${ }^{14}$

First, we run estimations at the aggregate level relying on either single-sector models using either average or median moments of the data or on multi-sector models where the definition of sectors correspond to the aggregate COICOP categories (food, manufacturing goods, energy and services for the 4-sector model; non-energy goods, services and energy for the 3-sector model; goods+services and energy for the 2 -sector model). Then, we estimate models at the product level for all of the 227 products of our micro price data set. In this case, the joint estimation of a multi-sector menu cost model with such a large number of sectors and parameters would not be tractable. To perform product-level estimations, we then follow a two-step approach. In a first step, we estimate a single sector version of our model based on the median moments of the aggregate economy. Following Nakamura and Steinsson (2010) and our own results (detailed in further section), this model captures rather well the behaviour of the aggregate economy. Then, in a second step, for each of the 227 sectors in turn, we estimate a two-sector model featuring i) a small sector, which is our sector of interest, and ii) a large sector which features the "rest of the economy". The parameters for the latter large sector are treated as fixed, auxiliary parameters and set to the values obtained in the first step. Estimation targets the moments calculated for each disaggregated product. The weight of the small sector in the overall economy is set small values of moment variances, they are bound to be very small and weakly informative.

${ }^{14}$ In Nakamura and Steinsson (2010), the frequency of regular price changes and the absolute size of price changes are used to estimate menu cost and the standard deviation of the productivity shock. Midrigan (2011) use 17 moments including quantiles of the distribution of price changes (10th, 25th, 50th, 75th, 90th percentiles) to estimate several parameters whereas more recently, Karadi and Reiff (2014) use interquartile range and kurtosis of the distribution of price changes to calibrate their model. 
to its value in the French CPI, whereas the weight of the large sector is set to the fraction of the total size CPI covered by our full sample. Overall, we thus estimate 227 two-sector general equilibrium models. Following this method, we are able to estimate sets of structural parameters for a large number of sectors, while relying on a general equilibrium approach. The potential bias stemming from having the small sector pooled with the other sectors at the estimation stage should remain very limited since the average product-level weight is less than $0.5 \%$.

\subsection{Aggregate results}

Table 4 first presents results obtained for a one-sector version of the model estimated using either median moments or mean moments. This allows to document the "bias" incurred when estimating the model with aggregate mean moments (as underlined by Nakamura and Steinsson (2010) with a CalvoPlus model calibrated on US data). We also report results obtained from a 4-sector version of our model (food, non-energy manufacturing goods, energy and services). Results also include the version of the model where we consider intermediate inputs in the production function of the firm (see Table 3 for actual and simulated moments).

One first salient result is that the value of $\lambda$ is rather high: price changes triggered under the zero menu cost regime accounts for about $60 \%$ of the median frequency of price changes and even more in the model with intermediate inputs. Thus, for the typical sector, the Calvo component of the model is rather large as compared to the menu cost component. This finding matches evidence reported on producer prices by Carlsson (2017) using Swedish micro data and Alvarez, Le Bihan, and Lippi (2016) on the same French CPI data using a sufficient statistics approach. To anticipate on the consequences for monetary policy, the "selection effect" typical of menu cost model is expected to be much attenuated in such a parameter configuration. Looking at differences across broad sectors, the Calvo component plays a larger role in energy and services. Moreover, $\lambda$ is much smaller for the model estimated with median moments (4.9\% vs $7.5 \%$ ); this result is quite consistent with Nakamura and Steinsson (2010) and comes from the asymmetry in the cross-section distribution of frequency of price changes (see below for more details at 
the product-level). The estimated average menu cost $\mu$ - when price adjustments are not free represents between 2 and $3 \%$ of total revenues. We can compute the average amount paid by firms per period for adjusting their prices as $\mu \times(f-\lambda)$ : in France, such average cost represents a little less than $0.1 \%$ of total revenues when we assume no intermediate inputs. Menu costs are a little larger in services but since the Calvo component is higher in this sector, the average amount paid by firms to adjust their prices is smaller in services than in manufacturing goods.

Concerning the parameters associated with the productivity process, the unconditional standard deviation of the productivity shock (say $V_{a}=\frac{\sigma_{\epsilon}}{\sqrt{\left(1-\rho^{2}\right)}}$ ) lies between $5 \%$ and $9 \%$. The volatility of idiosyncratic shocks is found to be large compared to the aggregate shock on inflation, since the standard deviation of $\eta_{t}$ is calibrated on aggregate CPI data to $\sigma_{\varepsilon}^{P}=0.28 \%$. Thus idiosyncratic productivity shocks are the main drivers of price change decisions and explain the dispersion in the size of price adjustment. The standard deviation of productivity shock is a little smaller in services (less than 0.05) than in manufacturing goods (more than 0.06).

In Table 5, we present results comparing estimates obtained using similar product coverage in both France and the United States ${ }^{15}$ On top of frequency and share of price increases, we here use the three quartiles of absolute price changes as targeted moments (instead of kurtosis and interquartile range). This set of moments allows us to use the moments reported by Nakamura and Steinsson (2008) for the United States and make possible the comparison with French data 16 To reduce computational burden, we only estimate here the one-sector version of the model estimated using in turn median moments or mean moments.

First, we find very close values of $\lambda$ in both countries (close to $5 \%$ in the model without intermediate inputs and close to $7 \%$ in the model with intermediate inputs). The Calvo component accounts for more than $70 \%$ of price changes in the case with intermediate inputs. The average

\footnotetext{
${ }^{15}$ In Table B in Appendix, we report actual and simulated moments generated by models for all US/FR estimations.

${ }^{16}$ This exercize can also be considered as a robustness exercize for our aggregate single-sector estimation using French data. We find only small differences in estimates for France using the two different sets of moments.
} 
menu cost $\mu$ is larger in the United States than in France (5 versus 3\% of total revenues). A larger menu cost $\mu$ is here needed to fit the larger size of price changes in the US, when at the same time frequencies of price changes and shares of price increases are rather similar in both countries. Overall, in France, the average menu cost actually paid represents between 0.05 and $0.1 \%$ of total revenues whereas in the US it is $0.2 \%$ when $s_{m}=0$ when and $0.1 \%$ when $s_{m}=0.7$. Nakamura and Steinsson (2010) report close results with an average menu cost actually paid of about $0.5 \%$ when $s_{m}=0$ and close to $0.1 \%$ when $s_{m}=0.7$. Studies using "direct" evidence such as Levy, Bergen, Dutta, and Venable (2005), Dutta, Bergen, Levy, and Venable (1999) or Zbaracki, Ritson, Levy, Dutta, and Bergen (2004) report values between $0.5 \%$ and $1 \%$ of revenues for different types of supermarkets, drugstores or industrial firms. Overall, menu costs are estimated to be larger in the United States - conditional on excluding from calculations sales and promotions and restricting to the set of "common products". On the contrary, the size of productivity shocks is estimated to be much larger in the United States (between 0.08 and 0.14) than in France (between 0.06 and 0.09). Nakamura and Steinsson (2010) report values between 6 and $10 \%$ for $\sigma_{\epsilon}$, which implies values between 8 and $13 \%$ for $V_{a}$. In our model, we find that differences in size of price adjustments between France and the United States is largely explained by differences in the variance of the productivity shock.

\subsection{Product-level estimates}

Figure 5 plots the weighted distribution of the parameters estimated for 227 disaggregated products available in our data set. For all four parameters of the model, the degree of heterogeneity is large. The distributions of $\lambda_{k}$ 's and $\mu_{k}$ 's feature the largest dispersion ${ }^{17}$ In Table 6 , we have reported some statistics of the distribution of parameters when $s_{m}=0$ and $s_{m}=0.7$. First, the median parameter estimates across the 227 different product-level estimates is strikingly closer to the parameters estimated with median moments. This reinforces our conjecture that

\footnotetext{
${ }^{17}$ Table 3 reports the average moments simulated by all the product-level parameters. In Appendix Figures A and $\mathrm{B}$ plot the simulated moments and actual moments for all sets of product-level moments.
} 
there is a bias when we estimate a single-sector specification using mean moments. Second, as expected, we find large variance in the distribution of pricing frictions parameters. The median and mean estimates are quite different for $\lambda$ and $\mu$ whereas they are almost the same for productivity parameters. Moreover, using the ratio between the interquartile difference (q3-q1) and the median of the distribution of parameters as a dispersion indicator, we find a larger dispersion for $\lambda$ and $\mu$ (dispersion ratio close to $1.2=\frac{0.071}{0.059}$ for $\lambda$ and $0.9=\frac{0.039}{0.044}$ for $\mu$ ) than for $\sigma$ and $\rho$ (dispersion indicators of $0.45=\frac{0.019}{0.042}$ and $0.04=\frac{0.028}{0.666}$ ). We obtain similar conclusions when looking at standard deviations of parameter distribution. Considering models with intermediate inputs modifies only slightly the conclusions, dispersion in productivity parameters is a little larger. Part of this dispersion in pricing friction parameters is due to the energy sector where the $\lambda$ parameter is very large. Removing parameters associated with energy products does not modify qualitatively our results. The median $\lambda$ estimate is now closer to the average $\lambda$ estimate (respectively 0.048 and 0.058 when $s_{m}=0$ ) whereas average and median parameters associated with productivity shocks are left quite unchanged. However, the relative dispersion remains very high for $\lambda$ and $\mu$ (respectively 1.3 and 1.0 when $s_{m}=0$ ) whereas dispersion indicators for productivity parameters are still low.

To illustrate how differences in price adjustment characteristics relate to structural parameters of price setting, Figures 6, 7, 8 and 9 plot each moment of the data against estimated parameters, across the 227 products. In most cases, no simple relationship emerges, illustrating that various parameters play a role. However, some patterns are noticeable. Figure 6 suggests that a large share of the cross-product heterogeneity in frequency of price changes is explained by variations of $\lambda$ and $\mu$, whereas productivity parameters play a smaller role. As expected, cross-product differences in the share of price increases seem negatively related to cross-product differences in productivity parameters, while the relation with menu-cost parameters is less clear-cut (Figure 7). Finally, from Figures 8 and 9, cross-product differences in the median size of price changes and in the dispersion of price change appear to be related with the 
variance of productivity shocks and of the menu cost $\mu$.

To investigate more formally to which extent cross-product heterogeneity in parameters can explain cross product heterogeneity in data moments, we run a series of counterfactual experiments. For each of the $227 \mathrm{CPI}$ product categories, we run four counterfactual exercizes, each corresponding to one the parameters of interest. In each exercize, we simulate moments from the multi-sector model holding one of the 4 parameters constant across sectors, and setting it equal to the median value of parameter estimates across products. For instance, in all sectors we set $\lambda_{k}$ equal to the median value of $\lambda$ 's, and for all product categories in turn, we simulate a model using actual estimated parameter values except for $\lambda$. We then calculate the relative dispersion of the cross-product distribution of the moments simulated by the counterfactual exercises (i.e. standard deviation divided by the mean) and compare it to the relative dispersion in the data. A low relative dispersion as compared to that in the data will indicate that heterogeneity in the parameter of interest contributes a lot to the heterogeneity observed for a given moment.

Table 7 summarizes the results. The relative dispersion across products of the frequency of price changes in the data is very large since the standard deviation is around 1.35 times the average frequency. When considering the counterfactual where $\lambda_{k}$ is set to its median value Median $\left(\lambda_{k}\right)$ for all products, the dispersion of the frequency of price changes is much lower (0.258). A large share of the dispersion in $\lambda_{k}$ is due to energy products since the high frequency of price changes in energy is captured in the model by a large Calvo parameter. The dispersion of the frequency lowers a lot when excluding energy (from 1.35 to 0.57 , see second panel of Table 7). However, heterogeneity in $\lambda_{k}$ is still the key contributor to variations in the frequency of price changes. Even excluding energy products, when $\lambda_{k}$ is set to its median value for all products the relative dispersion of the frequency of price changes is more than halved from $57.3 \%$ to $21.9 \%$. Productivity parameters play a minor role in explaining cross product heterogeneity in the frequency of price changes ${ }^{18}$

\footnotetext{
${ }^{18}$ The counterfactual cross-product relative dispersion in the frequency moment is even larger than the baseline relative dispersion when $\sigma_{\epsilon k}$ are set equal to their median. This reflects the fact that the $\rho_{k}$ and $\sigma_{\epsilon k}$ are negatively correlated across products.
} 
Turning to the share of price increases, the cross-product relative dispersion is rather small (21.5\%). $\lambda$ and $\sigma_{\epsilon}$ contribute, albeit to a limited extent, to explain this cross-product heterogeneity: the corresponding counterfactual relative dispersion is only reduced to $17.1 \%$ and 20.9\%. For that moment, parameters $\rho_{k}$ and the menu cost play an even more limited role. The relative dispersion in the median size of price changes does not seem to be driven by any single parameter. The cross product heterogeneity in the dispersion of price changes (as captured by the relative dispersion of interquartile of price changes), equal to $48.4 \%$, is related to cross product differences in $\sigma_{\epsilon k}$ parameters. Finally heterogeneity in kurtosis can be traced out to the Calvo parameter $\lambda$.

To summarize estimation and counterfactual exercizes, there is evidence of heterogeneity in all parameters. In particular we find evidence both of substantial "menu costs" and of a Calvo component in price adjustments. Heterogeneity in the frequency of price change is mainly driven by the pricing frictions parameters. In turn, heterogeneity in the idiosyncratic productivity/cost process plays more of a role explaining the smaller variability in size of price changes.

\section{Implications for Monetary Non Neutrality}

This section investigates to what extent cross-product heterogeneity, as well as the mix of timeand state-dependent pricing identified by our estimated set of parameters of the multi-sector menu cost model, do matter for the real effects of monetary policy. We investigate also whether differences in structural parameters between France and the United States have implications for the real effect of monetary policy in both countries 19 We focus for that purpose on a standard indicator of monetary non-neutrality: the cumulated response of output to a shock to nominal output (i.e. a shock to $\eta_{t}$ ). Impulse responses to a monetary policy shock can be generated in our set-up using function $\Gamma$ obtained from the Krusell and Smith (1998) procedure combined

\footnotetext{
${ }^{19}$ Obviously our exercize is primarily an analytical one: characterizing a realistic monetary policy shock would require a more sophisticated set-up, in particular because France is part of the European Monetary Union. However to the extent that existing studies of price rigidity point that price adjustment patterns in France are even quantitatively representative of those in the euro area, the exercize can be thought as a euro-area-wide shock.
} 
with the law of motion for aggregate output.

\subsection{The Amplification Effect of the Time vs State-Dependent Component}

We first compare the degree of non-neutrality of our baseline model with that resulting from two polar benchmark models our time-varying menu-cost model encompasses. One is a pure menu cost model in the vein of Golosov and Lucas (2007) $(\lambda=0)$. The other is a baseline Calvo model, corresponding to $\mu=0$. We also compare our results with the ones obtained with the CalvoPlus model estimated following the approach of Nakamura and Steinsson (2010) ${ }^{20}$ In this section, we perform comparisons between the different models using an aggregate single-sector model estimated using median moments of the data. Nakamura and Steinsson $(2010)$ have argued that such an approximation is appropriate, by contrast with using a single sector model calibrated on the average moments. The relevance of this approximation in our set-up is explored further in next section. Estimation results are summarized in Table $8{ }^{21}$ In terms of price rigidity parameters our model stands in between the menu cost and the Calvo model. As compared to the CalvoPlus, our baseline model appears closer to the menu cost model. Our metric here is the ratio of $\lambda$ (or, in the CalvoPlus model, of the low menu cost probability) to the frequency of price change (i.e. the fraction or free (or cheap) price changes). That fraction is smaller in our baseline set-up $(58.6 \%)$ than in the CalvoPlus one $(71.7 \%)$. By construction this fraction is respectively 0 and 1 in the menu cost and Calvo models.

Figure 11 plots the response of output to a monetary policy shock in our baseline model along with the three benchmark models. Unsurprisingly monetary policy non-neutrality in both the CalvoPlus model and our augmented menu-cost model is larger than in the standard menu-cost model, and lower than in the pure Calvo model. Columns 7 and 8 in Table 8 reports degrees of monetary non-neutrality for the different models. The amplification factor is of the order of

\footnotetext{
${ }^{20}$ Their set-up is quite related to our model but is different in at least two dimensions. First, in their model the menu cost is set to a small but positive value in the "low menu cost" case (versus 0 in our case). Furthermore, while in the approach by Nakamura and Steinsson (2010) the probability of a low menu-cost state is by assumption set equal to the frequency of price change, we freely estimate the Calvo parameter in our set-up.

${ }^{21}$ Table $\mathrm{C}$ in Appendix reports actual and simulated moments generated by the different models.
} 
2.2 , that is cumulated response of output is nearly twice larger than in a pure menu-cost model. This amplification effect is similar but a little smaller than the one we can obtain using estimates from the Nakamura and Steinsson (2010) framework on French CPI data. This amplification results here from the presence of a Calvo component in the variable menu-cost model.

According to our indicator of non-neutrality, the overall response is somewhat closer to the cumulated impulse response function from the Calvo model than the one coming from the menucost model. While our model has an amplification factor of about 2, the amplification factor is estimated to be about 3 for the Calvo model. This result comes from the large majority of price changes due to the Calvo mechanism. Alvarez, Le Bihan, and Lippi (2016) or Nakamura and Steinsson (2010) show that introducing a fraction of state-dependent agents in a Calvo set-up reduces non-neutrality more than proportionally. In other terms, the output response is a convex function of the share of Calvo price setters (for a given frequency of price change). The quantification of this effect we obtained is in line with Alvarez, Le Bihan, and Lippi (2016) 22

\subsection{Sectoral Heterogeneity and Monetary Non Neutrality}

To investigate implications of sectoral heterogeneity, we analyze the degree of monetary nonneutrality in the different variants of our model: a single-sector model calibrated to fit average moments across sectors, a one-sector model calibrated to fit median moments, and multi-sector models with alternative numbers of sectors. As previously mentioned, simulating a 227 sector general equilibrium multi-sector menu cost model would not be computationally feasible. Therefore, in this exercize we rely on multisector models, with a number of sectors ranging from two to up 19 sectors. We use two alternative approaches to design these multi-sector models. The first, and simpler approach, relies on pre-set lists of sector frequently used by macroeconomists, the same groups as the ones used for estimation of aggregate multi-sector models. By estimating the models at the chosen level of disaggregation, the moments generated by the model match

\footnotetext{
${ }^{22}$ Note the amplification effect of the pure Calvo set-up relative to pure menu cost, about 3 in our set-up, is found to be lower than in their analytical model, for which the amplification factor is 6 .
} 
quite precisely the aggregate moments of the economy (Table 3) 23 Our second strategy is to make use of the sets of parameters we have estimated at the product level (those summarized in Table 6). Following this approach, for a given number of sectors (say, 4) we sort all 227 product-level parameter sets according to the value of $\lambda \sqrt{24}$ For instance with four sectors, the first sector will group all products for which $\lambda_{k}$ is below the first quartile of $\lambda_{k}$ 's, the last sector will group all products with $\lambda_{k}$ above the third quartile of $\lambda$ 's. Then, in each sector we select a parameter set representative of this sector by picking the weighted average parameter in that sector. All models in this section can be viewed as approximations to the "true" data-generating model, that would be in our set-up a 227 sectors multi-sector model. To the extent that there is residual heterogeneity within each sector, our results will underestimate the bias of using a one-sector model rather than a multi-sector one. In the spirit of from Carvalho and Nechio (2017), we investigate how many sectors are needed to approximate an economy with a large number of sectors.

Figure 12 displays the response of output to a one standard deviation monetary policy shock in our various different exercizes (where $s_{m}=0$ ) whereas Table 9 reports the cumulated output response to a one-standard deviation monetary policy shock for all our models (this indicator being our proxy for the degree of monetary policy non-neutrality). Our first finding is that the response is much more short-lived and smaller in the one-sector model fitting the average moments of the data than in the various multisector models. Thus, the persistence is severely underestimated when neglecting sectoral heterogeneity. Real effects of monetary policy are 3 to 4 times larger in multi-sector models compared to the single-sector estimated using average moments. This finding echoes Carvalho (2006) (in a Calvo model) and Nakamura and Steinsson (2010) (in a CalvoPlus setup). A second finding is that a single-sector model calibrated on

\footnotetext{
${ }^{23}$ An alternative approach, taking the median of estimated parameters in each sector, leads to distorted simulated average moments at the aggregate level, implying in particular arguably biased comparisons, and a stronger effect of monetary policy.

${ }^{24}$ Findings from Carvalho and Nechio (2017) suggest that heterogeneity in $\lambda$ is the most relevant as far as macroeconomic persistence is concerned. We will report results using sorting of parameter sets according to other parameters.
} 
median moments provides a more persistent and larger effect than a single-sector estimated using average moments. The degree of non-neutrality is higher by a factor of 3.22 in the one-sector model using median moments than in the one using average moments. Results are qualitatively similar with $s_{m}=0.7$ although in that case, the persistence of output is larger for all models (see Appendix Figure $\mathrm{C}$ and Table $\mathrm{E}$ in Appendix). Third, a single-sector model estimated on median moments is a rather good approximation of the response of a multisector economy. We find that the output response function generated by the single-sector using median moments is very close to IRFs obtained with multi-sector models where the number of sectors is larger or equal than 3. The amplification factor (a little more than 3 ) is very similar to the ones we find for multi-sector models. Lastly, we investigate to which extent the number of sectors considered matters for the cumulated real effect of monetary policy. We find that considering a twosector model with energy and core inflation items is not enough to capture fully non-neutrality induced by the extent of sectoral heterogeneity. However, energy seems to play a rather large role in explaining the amplification of monetary non-neutrality due to sectoral heterogeneity: the amplification factor is 2.5 in the model featuring this simple two-sector economy compared to the model estimated using average moments. The degree of non-neutrality further increases when we decompose core inflation items into goods and services (Figure 12). However, decomposing goods into food and other manufactured goods does not provide additional real effects. The amplification factors are quite similar considering a 3- or a 4-sector model (3.5 compared to the single-sector average model). If we consider IRF generated in models considering more than 4 sectors by grouping products according to their $\lambda$ values, two results stand out. First, the overall degree of non neutrality is larger than with "predefined" sectors. Indeed the degree of heterogeneity is maximized when sorting according to estimated parameters, rather than using sectors defined by statistical consumption categories. In particular, a maximum amplification factor is obtained when we consider more than 5 sectors grouping products according to their $\lambda$ values; the amplification factor is between 4 and 5 . Grouping products according to values of $\mu$ or $\sigma$ would lead to lower amplification factors of about 3 to 4 , comparable to what we can 
obtain with a model with 3 different sectors (see Appendix Figure $\mathrm{D}$ for IRF when we group products according to $\mu$ or $\sigma$ values). Second, differences in IRF or degree of monetary nonneutrality are rather limited. Thus, the result in Carvalho and Nechio (2017) that a limited number sectors (3 in their analysis) nearly captures all the relevant heterogeneity in the data as far as monetary policy non neutrality is concerned, seem to hold in our set-up as well. Similar conclusions are obtained when including intermediate inputs (i.e. $s_{m}=0.7$ ) even if amplification factors compared to the single sector on average moments are quite smaller (about 2 or less) (see Figure $\mathrm{E}$ and Table $\mathrm{E}$ in Appendix)

Our results are quite in line with the results of Nakamura and Steinsson (2010) for the United States. Focusing on the variance rather than cumulated IRF, they find that the degree of monetary non-neutrality generated by a single-sector calibrated on median moments is 3 to 4 times higher than the one generated by a model calibrated on average moments. They also report an amplification factor of 4 with a 14 -sector model, which is in line with the range we find for a large multisector economy. The amplification effect related to sectoral heterogeneity we find on French data is also consistent with - yet quantitatively larger than - the analytical results of Alvarez, Le Bihan, and Lippi (2016): the amplification factor would be predicted close to 2.5 in Alvarez, Le Bihan, and Lippi (2016) with a full-heterogeneous model versus about 3 to 4.7 in our set-up (see Appendix for a more detailed comparison and Table D in Appendix for detailed results).

Overall, the main results on the monetary non-neutrality implications of sectoral heterogeneity are the following: a single-sector estimated on median moments provides an additional degree of monetary non-neutrality compared to a model estimated on average moments. The degree of monetary non-neutrality generated by a single-sector model using median moments is similar to the ones generated by multi-sectoral models. Energy contributes significantly to explain the gap between models estimated using mean and median moments. Our results also indicate that a model with as few as three sectors seems to be enough to approximate a full multi-sector model. Finally, heterogeneity in the Calvo component seems to contribute the most 
to the increase in monetary non-neutrality.

\subsection{France versus United States}

Finally, we explore differences in the degree of monetary non-neutrality between France and the United States (for which we have available detailed information on price rigidity). Here, our calibration implies that all parameters other than the "price-setting" parameters of interest are the same for both countries, so differences between the two countries can only be attributed to differences in productivity or menu costs.

Table 10 compares the degree of monetary non-neutrality obtained from single-sector models estimated using median moments on French and US micro data whereas Figure 13 plot impulse response functions to a one standard deviation monetary shock (when $s_{m}=0$ ). In Appendix Figure F plots the same IRF but considering the case $s_{m}=0.7$. We find quite small differences in the degree of non neutrality between France and the United States. The degree of non-neutrality is only a little larger in France than in the United States (0.0075 versus 0.0074). The difference is a little more pronounced when $s_{m}=0.7$. This suggests that differences in menu costs or productivity parameters cannot explain differences in monetary non-neutrality that may exists between these two countries 25

\section{Conclusion}

Motivated by the recurrent finding in empirical micro prices studies that prices are much more frequent in some sectors than others, this paper has investigated the role of menu costs, of the "time dependent" constraints on price adjustments, and of productivity shocks in the level, and in the cross-sectoral dispersion, of price rigidity in France. A structural model of price rigidity has been used to disentangle the effects of price rigidity on one side and of productivity shocks on the other side on the moments of price adjustment patterns (i.e. frequency and size

\footnotetext{
${ }^{25}$ We recall that this interpretation holds to the extent that sales -which are excluded from our analysis- are not regarded as mainly responding to aggregate shocks
} 
of price changes). The augmented menu cost model used nests both the standard Calvo model and a fixed menu-cost model. Using a SMM estimation technique and price rigidity moments computed on French CPI micro data, we have estimated deep parameters of this random menu cost model for more than 200 different CPI product categories. Matching US and French data moments, we have also compared estimation results for both United States and France.

Our main results are the following. First, the time-dependent dimension of price rigidity (the Calvo probability of free opportunity to change prices) is in our set-up crucial to fit the patterns of micro data and a large proportion of price changes are associated with the free opportunity to change prices. The "menu cost" component of price rigidity contributes to a lesser extent to rationalize patterns of price adjustment. Second, there is a substantial degree of heterogeneity in all structural parameters across sectors. The cross sectoral heterogeneity in the frequency of price changes in the data reflects large differences in price rigidity deep parameters rather than differences in productivity shocks. In particular, cross-sectoral variance of the Calvo parameter contributes a lot to the cross-sectoral variation in the frequency of price changes. Third, at the aggregate level, cross-product heterogeneity is found to matter for monetary policy. The degree of monetary non-neutrality in a multi-sector economy is up to 4 or 5 times as large as in a single sector model featuring the same average moments. For the purpose of measuring monetary policy non neutrality however, considering three sectors seems sufficient to capture the amplification implied by the heterogeneity in the data.

We find broadly similar results in the United States and France (assuming identical parameters for parameters other than those related to costs and price-setting friction), suggesting that potential differences in the degree of monetary non-neutrality between the two economies are not driven by differences in the rigidity of regular prices. 


\section{References}

Acemoglu, Daron, Ufuk Akcigit, Douglas Hanley, and William Kerr. 2016. "Transition to Clean Technology." Journal of Political Economy 124 (1):52-104.

Alvarez, Fernando, Herve Le Bihan, and Francesco Lippi. 2016. "The Real Effects of Monetary Shocks in Sticky Price Models: A Sufficient Statistic Approach." American Economic Review 106 (10):2817-51.

Alvarez, Luis J. and Pablo Burriel. 2010. "Micro-Based Estimates of Heterogeneous Pricing Rules: The United States vs. the Euro Area." Scandinavian Journal of Economics 112 (4):697722 .

Anderson, Eric, Benjamin A. Malin, Emi Nakamura, Duncan Simester, and Jn Steinsson. 2017. "Informational Rigidities and the Stickiness of Temporary Sales." Journal of Monetary Economics 90:64-93.

Baudry, L., H. Le Bihan, P. Sevestre, and S. Tarrieu. 2007. "What do Thirteen Million Price Records have to Say about Consumer Price Rigidity?" Oxford Bulletin of Economics and Statistics 69 (2):139-183.

Berardi, Nicoletta and Erwan Gautier. 2016. "Adjustments in consumer prices in France in periods of low inflation." Quarterly Selection of Articles 41.

Berardi, Nicoletta, Erwan Gautier, and Hervé Le Bihan. 2015. "More facts about prices: France before and during the great recession." Journal of Money, Credit and Banking 47 (8):pp. $1465-1502$.

Bils, Mark and Peter J. Klenow. 2004. "Some Evidence on the Importance of Sticky Prices." Journal of Political Economy 112 (5):947-985.

Blanco, Andres. 2017. "Optimal Inflation Target in an Economy with Menu Costs and a Zero Lower Bound ." Working paper, University of Michigan. 
Bouakez, Hafedh, Emanuela Cardia, and Francisco J. Ruge-Murcia. 2009. "The Transmission Of Monetary Policy In A Multisector Economy." International Economic Review 50 (4):12431266.

Burstein, Ariel and Christian Hellwig. 2006. "Prices and market shares in state-dependent pricing models." 2006 Meeting Papers 375, Society for Economic Dynamics.

Caballero, Ricardo J. and Eduardo M. R. A. Engel. 1999. "Explaining Investment Dynamics in U.S. Manufacturing: A Generalized (S,s) Approach." Econometrica 67 (4):783-826.

Carlsson, Mikael. 2017. "Microdata Evidence on the Empirical Importance of Selection Effects in Menu-Cost Models." Journal of Money Credit and Banking .

Carvalho, Carlos. 2006. "Heterogeneity in Price Stickiness and the Real Effects of Monetary Shocks." The B.E. Journal of Macroeconomics 6 (3):1-58.

Carvalho, Carlos and Oleksiy Kryvtsov. 2018. "Price Selection." Tech. rep., Bank of Canada. Carvalho, Carlos and Fernanda Nechio. 2017. "Approximating Multisector New Keynesian Models." Working Paper Series 2017-12, Federal Reserve Bank of San Francisco.

Coibion, Olivier, Yuriy Gorodnichenko, and Gee Hee Hong. 2015. "The Cyclicality of Sales, Regular and Effective Prices: Business Cycle and Policy Implications." American Economic Review 105 (3):993-1029.

Costain, James and Anton Nakov. 2011. "Price Adjustments in a General Model of StateDependent Pricing." Journal of Money, Credit and Banking 43:385-406.

. 2012. "Distributional dynamics under smoothly state-dependent pricing." Journal of Monetary Economics forthcoming.

Dhyne, Emmanuel, Luis J. Alvarez, Herve Le Bihan, Giovanni Veronese, Daniel Dias, Johannes Hoffmann, Nicole Jonker, Patrick Lunnemann, Fabio Rumler, and Jouko Vilmunen. 2006. 
"Price Changes in the Euro Area and the United States: Some Facts from Individual Consumer Price Data." Journal of Economic Perspectives 20 (2):171-192.

Dhyne, Emmanuel, Catherine Fuss, M. Hashem Pesaran, and Patrick Sevestre. 2011. "Lumpy Price Adjustments: A Microeconometric Analysis." Journal of Business 6 Economic Statistics 29 (4):529-540. URL https://ideas.repec.org/a/bes/jnlbes/v29i4y2011p529-540. html.

Dixon, Huw David and Kun Tian. 2017. "What We can Learn About the Behaviour of Firms from the Average Monthly Frequency of Price-Changes: An Application to the UK CPI Data." Oxford Bulletin of Economics and Statistics 79 (6):907-932.

Dotsey, Michael, Robert G. King, and Alexander L. Wolman. 1999. "State-Dependent Pricing And The General Equilibrium Dynamics Of Money And Output." The Quarterly Journal of Economics 114 (2):655-690.

Dutta, Shantanu, Mark Bergen, Daniel Levy, and Robert Venable. 1999. "Menu Costs, posted prices and multiproduct retailers." The Journal of Money, Credit and Banking 31 (4):683-703.

Eichenbaum, Martin S., Nir Jaimovich, Sergio Rebelo, and Josephine Smith. 2014. "How Frequent Are Small Price Changes?" American Economic Journal: Macroeconomics 6 (2):137155.

Eusepi, Stefano, Bart Hobijn, and Andrea Tambalotti. 2011. "CONDI: A Cost-of-NominalDistortions Index." American Economic Journal: Macroeconomics 3 (3):53-91.

Fougere, Denis, Herve Le Bihan, and Patrick Sevestre. 2007. "Heterogeneity in Consumer Price Stickiness: A Microeconometric Investigation." Journal of Business \&3 Economic Statistics $25: 247-264$.

Gagnon, Etienne, J. David Lopez-Salido, and Jason A. Sockin. 2015. "The Cyclicality of Sales, 
Regular and Effective Prices: Comment." Finance and Economics Discussion Series 2015-52, Board of Governors of the Federal Reserve System (U.S.).

Golosov, Mikhail and Robert E. Jr. Lucas. 2007. "Menu Costs and Phillips Curves." Journal of Political Economy 115:171-199.

Hobijn, Bart, Federico Ravenna, and Andrea Tambalotti. 2006. "Menu Costs at Work: Restaurant Prices and the Introduction of the Euro." The Quarterly Journal of Economics $121(3): 1103-1131$.

Karadi, Peter and Adam Reiff. 2014. "Menu Costs, Aggregate Fluctuations, and Large Shocks." Working Paper Series 10138, CEPR.

Klenow, J. Peter and Benjamin Malin. 2010. "Microeconomic Evidence on Price-Setting." Handbook of monetary economics 3:231-284.

Klenow, Peter J. and Oleksiy Kryvtsov. 2008. "State-Dependent or Time-Dependent Pricing: Does It Matter for Recent U.S. Inflation?" The Quarterly Journal of Economics 123 (3):863904.

Krusell, Per and Anthony A. Smith. 1998. "Income and Wealth Heterogeneity in the Macroeconomy." Journal of Political Economy 106 (5):867-896.

Kryvtsov, Oleksiy and Nicolas Vincent. 2014. "On the Importance of Sales for Aggregate Price Flexibility." Staff Working Papers 14-45, Bank of Canada.

Le Bihan, Herve and Julien Matheron. 2012. "Price Stickiness and Sectoral Inflation Persistence: Additional Evidence." Journal of Money, Credit and Banking 44 (7):1427-1442.

Levy, Daniel, Mark Bergen, Shantanu Dutta, and Robert Venable. 2005. "The Magnitude of Menu Costs: Direct Evidence from Large U.S. Supermarket Chains." Macroeconomics 0505012, EconWPA. 
Luo, Shaowen and Daniel Villar. 2015. "The Skewness of the Price Change Distribution: A New Touchstone for Sticky Price Models." mimeo, Columbia University.

Midrigan, Virgiliu. 2011. "Menu Costs, Multi-Product Firms, and Aggregate Fluctuations." Econometrica, 79 (4):1139-1180.

Nakamura, Emi and Jon Steinsson. 2008. "Five Facts about Prices: A Reevaluation of Menu Cost Models." The Quarterly Journal of Economics 123 (4):1415-1464.

_ 2010. "Monetary Non-Neutrality in a Multisector Menu Cost Model." The Quarterly Journal of Economics 125 (3):961-1013.

—. 2013. "Price Rigidity: Microeconomic Evidence and Macroeconomic Implications." Annual Review of Economics 5 (1):133-163.

Pasten, Ernesto, Raphael Schoenle, and Michael Weber. 2017. "Monetary Policy Shocks in a Heterogeneous Production Economy." Working paper, Brandeis University.

Sheshinski, Eytan and Yoram Weiss. 1977. "Inflation and Costs of Price Adjustment." Review of Economic Studies 44 (2):287-303.

Woodford, Michael. 2009. "Information-Constrained State-Dependent Pricing." Journal of Monetary Economics 56:s100-s124.

Zbaracki, Mark J., Mark Ritson, Daniel Levy, Shantanu Dutta, and Mark Bergen. 2004. "Managerial and Customer Costs of Price Adjustment: Direct Evidence from Industrial Markets." The Review of Economics and Statistics 86 (2):514-533. 


\section{Tables and Figures}

Table 1: Stylized Facts on Price Rigidity in France (1994-2014)

\begin{tabular}{|c|c|c|c|c|c|c|c|}
\hline & \multirow{2}{*}{$\begin{array}{c}\mathrm{Nb} \\
\text { products }\end{array}$} & \multirow{2}{*}{$\begin{array}{c}\text { Freq. } \\
\text { changes }\end{array}$} & \multirow{2}{*}{$\begin{array}{l}\text { Share of } \\
\text { increases }\end{array}$} & \multicolumn{3}{|c|}{ Size of price changes } & \multirow{2}{*}{$\begin{array}{c}\text { CPI } \\
\text { Weight }\end{array}$} \\
\hline & & & & Median & Interquartile & Kurtosis & \\
\hline & \multicolumn{7}{|c|}{ Mean } \\
\hline All & 227 & 0.137 & 0.710 & 0.047 & 0.073 & 5.287 & 57.0 \\
\hline & \multicolumn{7}{|c|}{ Median } \\
\hline All & 227 & 0.084 & 0.674 & 0.044 & 0.070 & 4.462 & 57.0 \\
\hline Food & 77 & 0.132 & 0.609 & 0.044 & 0.081 & 3.995 & 15.3 \\
\hline Durables & 33 & 0.050 & 0.603 & 0.072 & 0.121 & 3.850 & 5.2 \\
\hline Other Manuf & 59 & 0.075 & 0.674 & 0.043 & 0.076 & 4.727 & 12.7 \\
\hline Energy & 6 & 0.744 & 0.609 & 0.028 & 0.055 & 2.804 & 5.0 \\
\hline Services & 52 & 0.049 & 0.898 & 0.041 & 0.037 & 6.347 & 18.8 \\
\hline
\end{tabular}

Note: Calculations made on the French CPI micro data set over the period 1994-2014 (25 million of monthly price quotes). Prices of rents, cars, fresh food products and electricity + clothing goods are excluded (around $60 \%$ of the CPI left). Price changes due to sales and promotions are excluded (flag). We have dropped VAT change and euro-cash changeover periods and price changes smaller than $1 \%$ in absolute values. Price rigidity moments are first calculated at the product level and we then compute the weighted median of those product-specific moments. The median price change is calculated using price changes in absolute values whereas interquartiles and kurtosis are calculated using price changes not in absolute values. 
Table 2: Comparison of French and US Price Rigidity Indicators

\begin{tabular}{|c|c|c|c|c|c|}
\hline & \multirow{2}{*}{$\begin{array}{l}\text { Freq. } \\
\text { changes }\end{array}$} & \multirow{2}{*}{$\begin{array}{l}\text { Share of } \\
\text { increases }\end{array}$} & \multicolumn{3}{|c|}{ Size of price changes } \\
\hline & & & p25 & p50 & p75 \\
\hline \multicolumn{6}{|l|}{ Mean } \\
\hline France & 0.139 & 0.708 & 0.028 & 0.049 & 0.087 \\
\hline United States & 0.149 & 0.694 & 0.039 & 0.085 & 0.171 \\
\hline \multicolumn{6}{|l|}{ Median } \\
\hline France & 0.084 & 0.674 & 0.026 & 0.045 & 0.080 \\
\hline United States & 0.092 & 0.689 & 0.038 & 0.080 & 0.155 \\
\hline
\end{tabular}

Note: Calculations made on the French CPI micro data set over the period 1994-2014 (25 million of monthly price quotes). Prices of rents, cars, fresh food products and electricity + clothing goods are excluded (around $60 \%$ of the CPI left). Price changes due to sales and promotions are excluded (flag). We have dropped VAT change and euro-cash changeover periods and price changes smaller than $1 \%$ in absolute values. Price rigidity moments are first calculated at the product level and we then compute the weighted (using French CPI weights median of those product-specific moments. For the US calculations, we are using moments calculated by Nakamura and Steinsson $(2008)$ and released as a web appendix. We are using moments at the product level and for comparable French products, we are considering moments excluding sales (flag for the frequencies and filtered for the size of price changes). We calculate aggregate moments using French CPI weights. 
Table 3: Actual and Simulated Moments from the Estimated Models

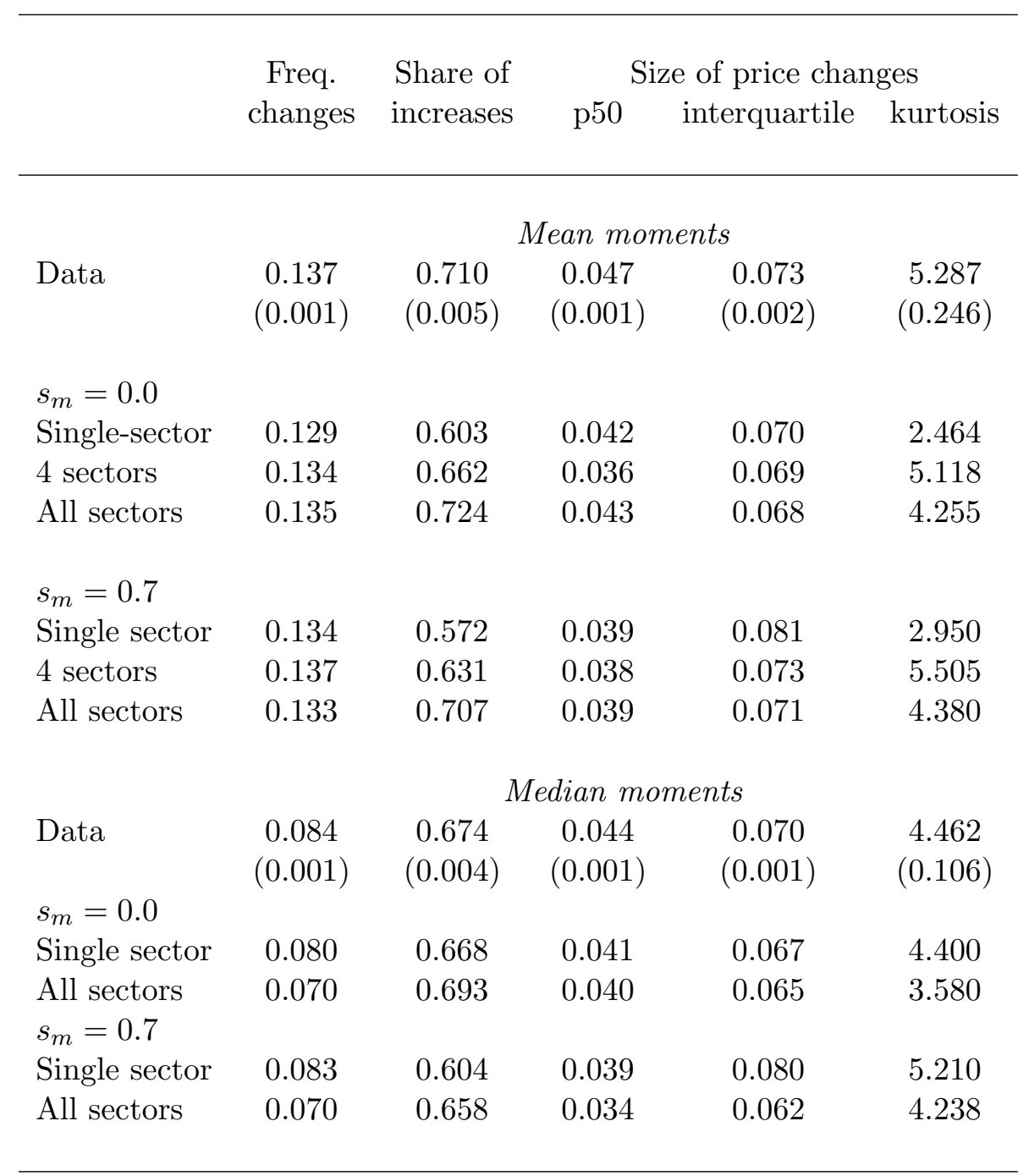

Note: Calculations made on the French CPI micro data set over the period 1994-2014 (25 million of monthly price quotes). Price rigidity moments are first calculated at the product level and we then compute the weighted (using French CPI weights) median of those product-specific moments. Standard deviation of moments are calculated using 100 bootstrap simulations. Moments generated by the models (single aggregate sector (single median / mean moments), 4-sector model (using mean moments by broad sector), two-sector models for all 227 products) at estimated values are also reported for cases where $s_{m}=0$ or $s_{m}=0.7$. 
Table 4: Estimates of Price Rigidity Model - Aggregate models

\begin{tabular}{|c|c|c|c|c|c|c|c|}
\hline & \multicolumn{3}{|c|}{ Menu cost } & \multicolumn{3}{|c|}{ Productivity } & \multirow[b]{2}{*}{$\frac{\lambda}{\text { Frec }}$} \\
\hline & $\lambda$ & $\mu$ & average & $\sigma_{\epsilon}$ & $\rho$ & $\sigma$ & \\
\hline \multicolumn{8}{|l|}{$s_{m}=0$} \\
\hline & \multicolumn{7}{|c|}{ Single sector } \\
\hline Median moments & 0.049 & 0.024 & 0.079 & 0.038 & 0.653 & 0.051 & 58.9 \\
\hline \multirow[t]{2}{*}{ Mean moments } & 0.075 & 0.011 & 0.061 & 0.027 & 0.739 & 0.039 & 56.2 \\
\hline & \multicolumn{7}{|c|}{ 4-sector model } \\
\hline Food & 0.101 & 0.047 & 0.139 & 0.049 & 0.722 & 0.071 & 77.0 \\
\hline Manuf. goods & 0.048 & 0.045 & 0.126 & 0.044 & 0.727 & 0.064 & 62.5 \\
\hline Energy & 0.724 & 0.061 & 0.000 & 0.037 & 0.641 & 0.049 & 100 \\
\hline Services & 0.041 & 0.062 & 0.052 & 0.033 & 0.714 & 0.047 & 82.5 \\
\hline \multicolumn{8}{|l|}{$s_{m}=0.7$} \\
\hline & \multicolumn{7}{|c|}{ Single sector } \\
\hline Median moments & 0.068 & 0.027 & 0.045 & 0.063 & 0.714 & 0.090 & 79.5 \\
\hline \multirow[t]{2}{*}{ Mean moments } & 0.099 & 0.009 & 0.032 & 0.043 & 0.712 & 0.061 & 72.1 \\
\hline & \multicolumn{7}{|c|}{ 4-sector model } \\
\hline Food & 0.125 & 0.049 & 0.057 & 0.076 & 0.739 & 0.112 & 91.3 \\
\hline Manuf. goods & 0.064 & 0.053 & 0.075 & 0.084 & 0.724 & 0.122 & 81.1 \\
\hline Energy & 0.758 & 0.071 & 0.000 & 0.043 & 0.654 & 0.056 & 100 \\
\hline Services & 0.054 & 0.068 & 0.011 & 0.062 & 0.703 & 0.087 & 97.0 \\
\hline
\end{tabular}

Note: The table reports results obtained from the simulated moments matching procedure. $\mu$ is here calculated as $\frac{\mu}{\frac{\theta}{\theta-1} Y_{S} S}$ whereas the average menu cost is calculated as $m u \times($ Freq $-\lambda) \cdot \frac{\lambda}{\text { Freq }}$ : fraction of price changes performed under $c_{t}=0$. Three different types of models are considered. Single-sector model consists of a model with only one sector and is estimated using either median moments of the data or average moments of the data. The four-sector model consists of a model with four different sectors: food, non-energy non-food manufacturing goods, energy and services. This model is estimated using mean moments of the different sectors. We also consider separately models where $s_{m}=0$ or $s_{m}=0.7$. 
Table 5: Estimates of Single Sector Price Rigidity Model - France vs United States

\begin{tabular}{|c|c|c|c|c|c|c|c|}
\hline & \multicolumn{3}{|c|}{ Menu cost } & \multicolumn{3}{|c|}{ Productivity } & \multirow[b]{2}{*}{$\frac{\lambda}{\text { Freq }}$} \\
\hline & $\lambda$ & $\mu$ & $\begin{array}{c}\text { average } \\
\text { (in \%) }\end{array}$ & $\sigma_{\epsilon}$ & $\rho$ & $\sigma$ & \\
\hline \multicolumn{8}{|l|}{$s_{m}=0.0$} \\
\hline France & 0.050 & 0.031 & 0.107 & 0.039 & 0.722 & 0.057 & 58.2 \\
\hline United States & 0.044 & 0.051 & 0.234 & 0.067 & 0.616 & 0.084 & 48.2 \\
\hline \multicolumn{8}{|l|}{$s_{m}=0.7$} \\
\hline France & 0.066 & 0.031 & 0.049 & 0.061 & 0.747 & 0.092 & 79.9 \\
\hline United States & 0.071 & 0.049 & 0.140 & 0.105 & 0.658 & 0.140 & 70.7 \\
\hline
\end{tabular}

Note: The table reports results obtained from the simulated moments matching procedure. For each category, we report the median parameter obtained. $\mu$ is here calculated as $\frac{\mu}{\frac{\theta}{\theta-1} Y_{S S}}$ whereas the average menu cost is calculated as $m u \times($ Freq $-\lambda) \cdot \frac{p_{0}}{\text { Freq }}$ : fraction of price changes performed under $c_{t}=0$. One-sector models are estimated using aggregate median moments US versus France. 
Table 6: Estimates of Price Rigidity Model - Product-level models

\begin{tabular}{|c|c|c|c|c|c|c|c|}
\hline & \multicolumn{3}{|c|}{ Menu cost } & \multicolumn{3}{|c|}{ Productivity } & \multirow[b]{2}{*}{$\frac{\lambda}{\text { Freq }}$} \\
\hline & $\lambda$ & $\mu$ & average & $\sigma_{\epsilon}$ & $\rho$ & $\sigma$ & \\
\hline & \multicolumn{7}{|c|}{$s_{m}=0.0$} \\
\hline Mean & 0.118 & 0.055 & 0.101 & 0.042 & 0.653 & 0.056 & 69.6 \\
\hline Median & 0.059 & 0.044 & 0.098 & 0.042 & 0.666 & 0.057 & 68.4 \\
\hline Interquartile & 0.071 & 0.039 & 0.084 & 0.019 & 0.028 & 0.026 & 0.23 \\
\hline \multirow[t]{2}{*}{ Std dev. } & 0.201 & 0.032 & 0.077 & 0.016 & 0.070 & 0.021 & 0.17 \\
\hline & \multicolumn{7}{|c|}{$s_{m}=0.7$} \\
\hline Mean & 0.147 & 0.099 & 0.043 & 0.057 & 0.738 & 0.090 & 91.9 \\
\hline Median & 0.072 & 0.109 & 0.022 & 0.058 & 0.745 & 0.093 & 94.9 \\
\hline Interquartile & 0.093 & 0.099 & 0.041 & 0.044 & 0.103 & 0.068 & 0.11 \\
\hline Std dev. & 0.238 & 0.055 & 0.070 & 0.031 & 0.096 & 0.056 & 0.10 \\
\hline
\end{tabular}

Note: The table reports results obtained from the simulated moments matching procedure. $\mu$ is here calculated as $\frac{\mu}{\frac{\theta}{\theta-1} Y_{S} S}$ whereas the average menu cost is calculated as $m u \times($ Freq $-\lambda) \cdot \frac{\lambda}{\text { Freq }}$ : fraction of price changes performed under $c_{t}=0$. We here report statistics calculated on the distribution of product-level parameters obtained from the estimation of our 227 product-level parameters. Statistics are weighted using CPI-weights at the product level. 
Table 7: Counterfactual Relative Dispersion of the Cross-Product Distribution of Moments

\begin{tabular}{lccccc}
\hline & \multicolumn{6}{c}{ Counterfactual exercizes } \\
& Data & \multicolumn{2}{c}{ under homogeneity in: } \\
& & $\lambda$ & $\mu$ & $\sigma_{\epsilon}$ & $\rho$ \\
\hline & & & & & \\
All products & 1.350 & 0.258 & 1.343 & 1.349 & 1.334 \\
Frequency & 0.215 & 0.171 & 0.209 & 0.181 & 0.221 \\
Share of price increases & 0.425 & 0.601 & 0.660 & 0.442 & 0.466 \\
Median size & 0.483 & 0.632 & 0.790 & 0.437 & 0.564 \\
Interquartile (q3-q1) & 0.416 & 0.390 & 0.597 & 0.605 & 0.605 \\
Kurtosis & & & & & \\
& & & & & \\
Excluding Energy & 0.573 & 0.219 & 0.541 & 0.533 & 0.592 \\
Frequency & 0.201 & 0.167 & 0.197 & 0.165 & 0.209 \\
Share of price increases & 0.421 & 0.592 & 0.650 & 0.450 & 0.459 \\
Median size & 0.495 & 0.612 & 0.796 & 0.452 & 0.575 \\
Interquartile (q3-q1) & 0.413 & 0.393 & 0.588 & 0.589 & 0.609 \\
Kurtosis & & & & & \\
& & & & &
\end{tabular}

Note: We here report relative dispersion indicators computed as the standard deviation of the distribution across products of moments divided by the mean value of moments (statistics are weighted). For instance, the standard deviation of the frequency of price change is $140 \%$ higher than the average frequency of price change. The first column reports the relative dispersion observed in the data. The second column the relative dispersion in the counterfactual exercise where we set $\lambda$ equal to its median value for all products of the sample and other parameters equal to their estimated value. Column (3), (4) and (5) report similar figures but using counterfactual exercises where the parameter set to its median value is respectively $\mu, \sigma_{\epsilon}$ and $\rho$. 
Table 8: Price Rigidity Models - Calvo, menu cost and variable menu cost models

\begin{tabular}{lcccccccc}
\hline & \multicolumn{2}{c}{ Menu cost } & \multicolumn{2}{c}{ Productivity } & & $\begin{array}{c}\text { Cumulated } \\
\text { real effect }\end{array}$ & $\begin{array}{c}\text { Amplification } \\
\text { Factor }\end{array}$ \\
& $\lambda$ & & & & & & \\
& & & average & $\sigma_{\epsilon}$ & $\rho$ & $\frac{\lambda}{\text { Freq }}$ & & \\
\hline Menu cost & 0.000 & 0.006 & 0.020 & 0.681 & 0 & 0.0040 & 1.00 \\
Baseline & 0.049 & 0.079 & 0.038 & 0.653 & 0.586 & 0.0087 & 2.20 \\
NS 2010 & 0.084 & 0.077 & 0.050 & 0.563 & 0.717 & 0.0079 & 1.99 \\
Calvo & 0.084 & 0.000 & 0.089 & 0.799 & 1 & 0.0113 & 2.85 \\
& & & & & & & \\
\hline
\end{tabular}

Note: The table reports results obtained from the simulated moments matching procedure for 4 different menu-cost models. $\mu$ is here calculated as $\frac{\mu}{\frac{\theta}{\theta-1} Y_{S} S}$ whereas the average menu cost is calculated as

$m u \times($ Freq $-\lambda) \cdot \frac{\lambda}{\text { Freq }}$ : fraction of price changes performed under $c_{t}=0$. We also report in this table the cumulated real monetary effect (calculated after 50 months) of a one-standard deviation money shock $(0.3 \%)$ in different models (col 7 and 8). First line reports the results for a Menu-cost model estimated on our aggregate median weighted moments. Second line reports the results for our baseline model (menu cost with possibility of free price adjustment). Third line reports the results using the Nakamura and Steinsson (2010)'s CalvoPlus model. Fourth line reports the results in a Calvo model estimated on our aggregate median moments. Amplification factor is the ratio of line (1) to other lines. 
Table 9: Cumulated Real Output Effect of a Monetary Shock - Single versus Multi-Sector Model

\begin{tabular}{lcc}
\hline & $\begin{array}{c}\text { Cumulated } \\
\text { real effects }\end{array}$ & $\begin{array}{c}\text { Amplification } \\
\text { Factor }\end{array}$ \\
& & \\
\hline Single sector (Mean moments) & 0.0027 & 1 \\
Single sector (Median moments) & 0.0087 & 3.22 \\
Multi-sector models (Mean moments) & & \\
2-sector model (Core - Energy) & 0.0068 & 2.49 \\
3-sector model (Manuf - Services - Energy) & 0.0094 & 3.47 \\
4-sector model (Food Manuf - Services - Energy) & 0.0093 & 3.44 \\
& & \\
Multi-sector models (product-level parameters) - 5 to 19 sectors & \\
$\lambda$ & {$[0.0105 ; 0.0127]$} & {$[3.87 ; 4.70]$} \\
$\mu$ & {$[0.0081 ; 0.0103]$} & {$[2.98 ; 3.81]$} \\
$\sigma$ & {$[0.0084 ; 0.0107]$} & {$[3.10 ; 3.96]$} \\
& & \\
\hline
\end{tabular}

Note: We report in this table the cumulated real monetary effect (calculated after 50 months) of a one-standard deviation money shock $(0.3 \%)$ in different models. A first group of results (lines 1 and 2) report the results for our baseline model (menu cost with possibility of free price adjustment) estimated on aggregate weighted moments (mean and median). A second group of results reports the results of multi-sector models estimated on sectoral weighted moments (mean moments calculated for COICOP broad sectors). A last group of results uses parameters from our two-sector models estimated for our 227 products. We here report real effects for different grouping of products (from 5 to 19 groups of products). We first sort product parameters according to the estimated values of one given parameter $(\lambda, \mu$ or $\sigma)$. We then group products according to their position on the distribution of this given parameters. We then calculate for each group the median value of all parameters in this group. Finally, we estimate the real effects of monetary policy considering a multi-sector model made of these groups of products. We are reporting the minimum and the maximum values we obtain for models with 5 to 19 groups of products. Amplification factor is the ratio of line (1) to other lines. 
Table 10: Cumulated Real Output Effect of a Monetary Shock - Single-Sector Models

\begin{tabular}{lcccc}
\hline & \multicolumn{2}{c}{$s_{m}=0$} & \multicolumn{2}{c}{$s_{m}=0.7$} \\
& $\begin{array}{c}\text { Cumulated } \\
\text { real effect }\end{array}$ & $\begin{array}{c}\text { Amplification } \\
\text { Factor }\end{array}$ & $\begin{array}{c}\text { Cumulated } \\
\text { real effect }\end{array}$ & $\begin{array}{c}\text { Amplification } \\
\text { Factor }\end{array}$ \\
\hline France (single, median) & 0.0075 & 1 & 0.0242 & 1 \\
United States (single, median) & 0.0074 & 0.98 & 0.0203 & 0.84 \\
\hline
\end{tabular}

Note: We report in this table the cumulated real monetary effect (calculated after 50 months) of a one-standard deviation money shock $(0.3 \%)$ in single-sector models estimated using French or US data (the share of intermediate inputs is assumed to be 0$)$. 
Figure 1: Frequency of Price Changes and Share of Price Increases
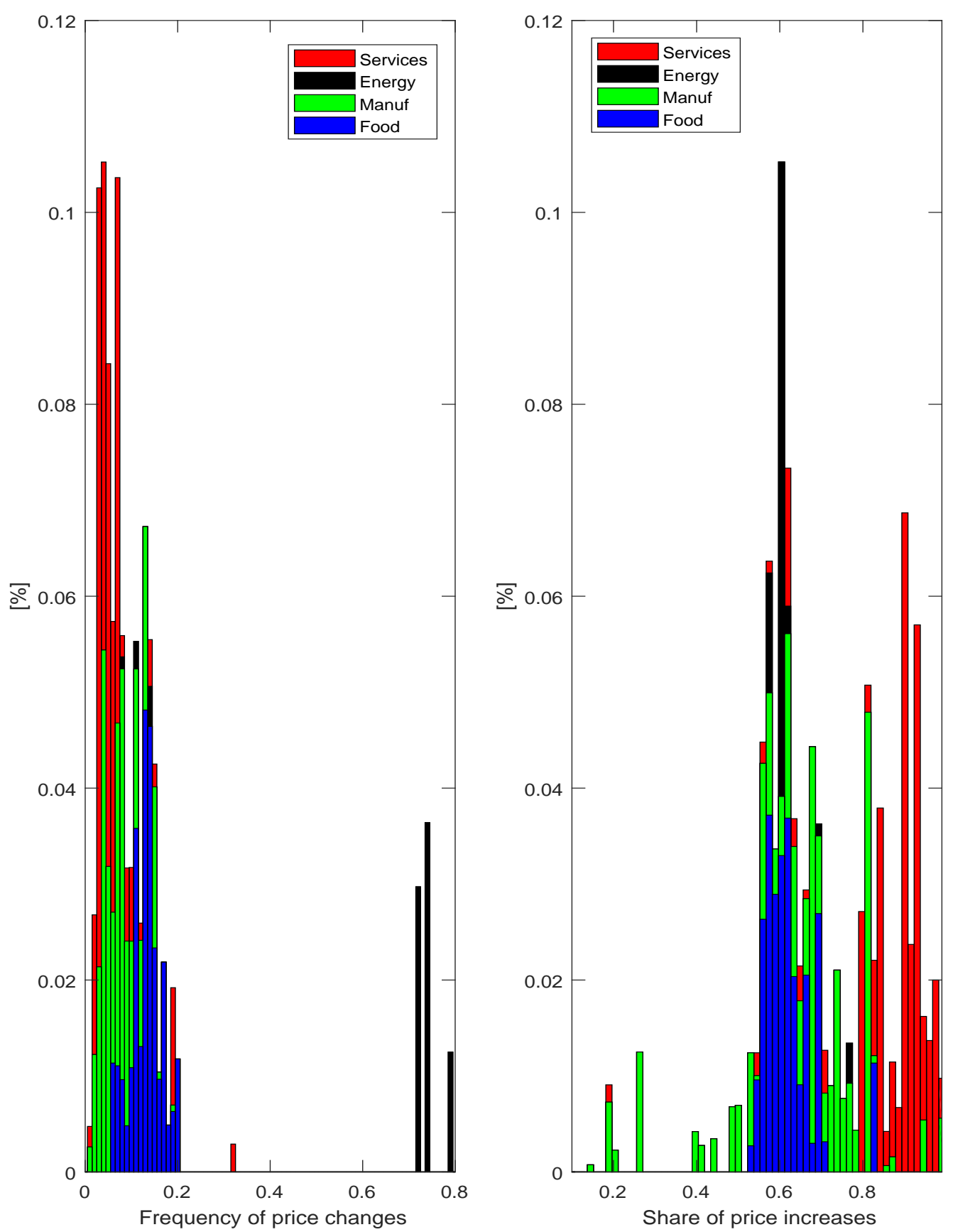

Note: The figure plots the distribution of the product-level frequency of price changes, frequency of price changes is computed using micro price data excluding price changes due to sales and product substitutions and price changes smaller than $1 \%$ in absolute values. 
Figure 2: Size of Price Changes (Median - Interquartile and Kurtosis)
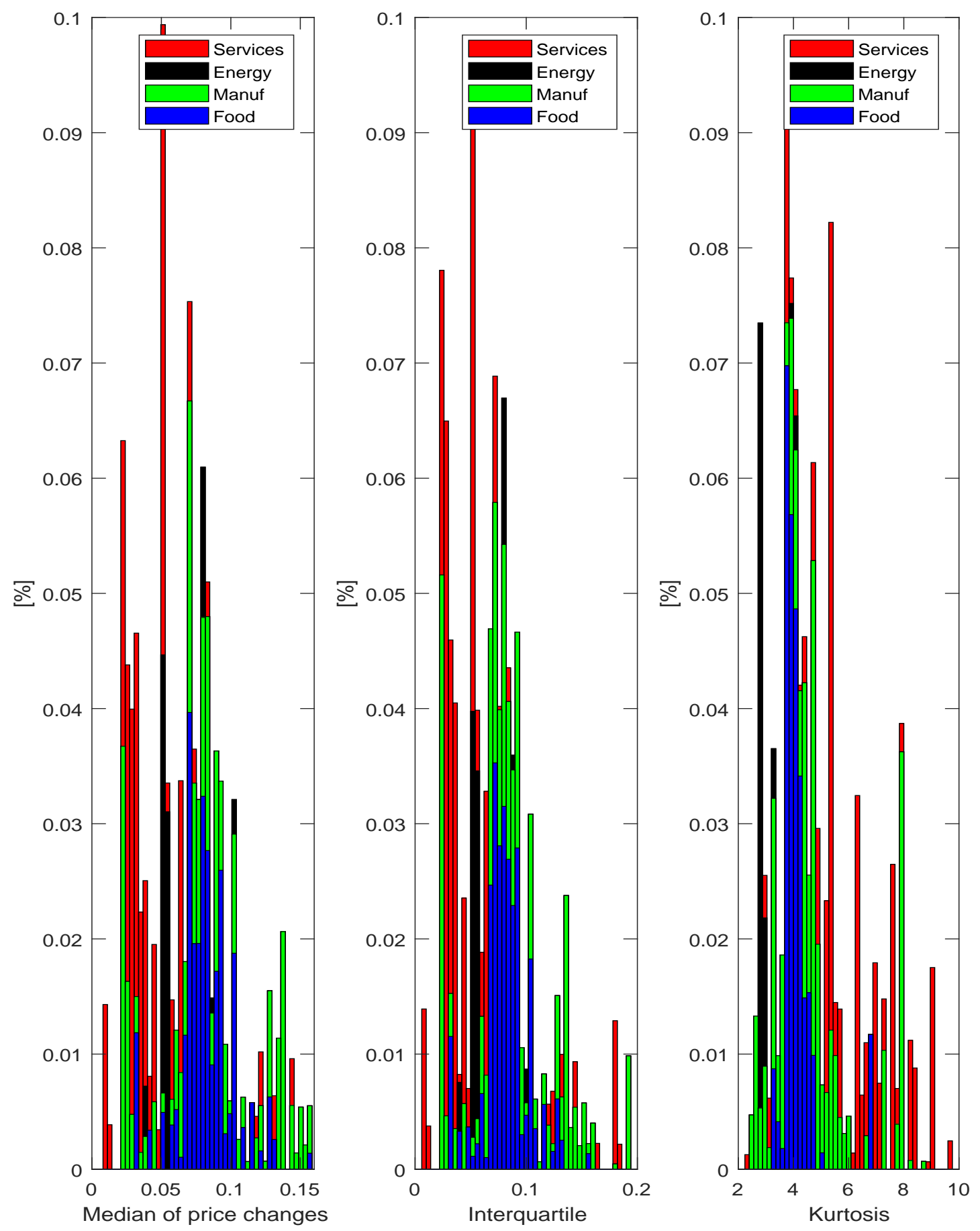

Note: The figure plots the cross product distribution of moments of the price change distribution: median price change (in absolute value), the interquartile price change (difference between the first and third quartile of price change), kurtosis of price change distribution. 
Figure 3: Moments of the Model as a Function of Menu Cost Parameters
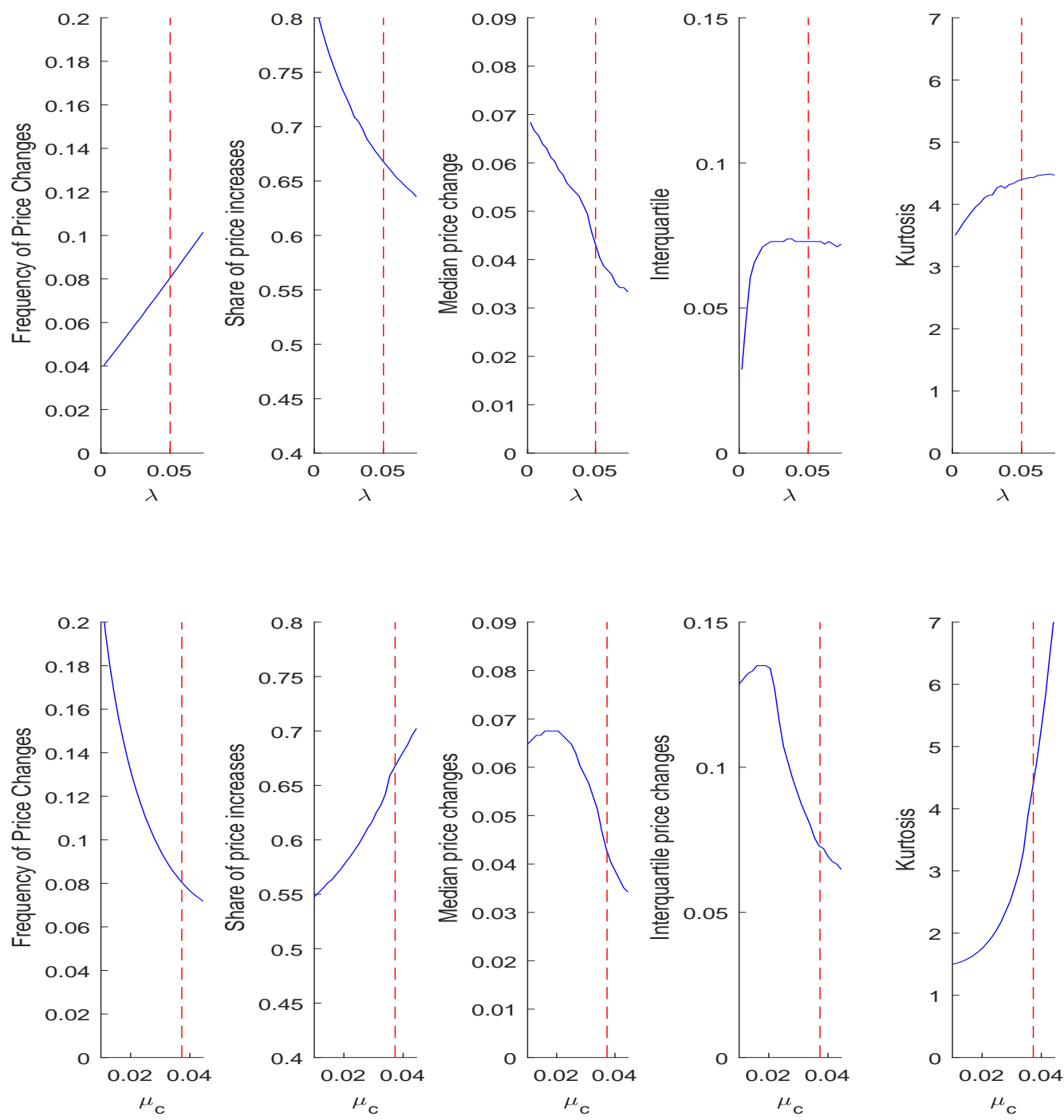

Note: Moments are simulated moments obtained from our model for a range of values of $\lambda$ (first row) and of $\mu$ (second row). We assume that other parameters are fixed to a baseline value $(\lambda=0.050, \mu=0.037, \sigma=0.038$, $\rho=0.69)$. The simulated model is a two-sector model $(K=2)$, featuring one small sector and one large sector. We run large simulations of the model under various parametrizations: each parameter in the small sector varies in turn on a grid, away from a baseline parameter value. The parameters of the larger sector are left unchanged across simulations. 
Figure 4: Moments of the Model as a Function of Productivity Parameters
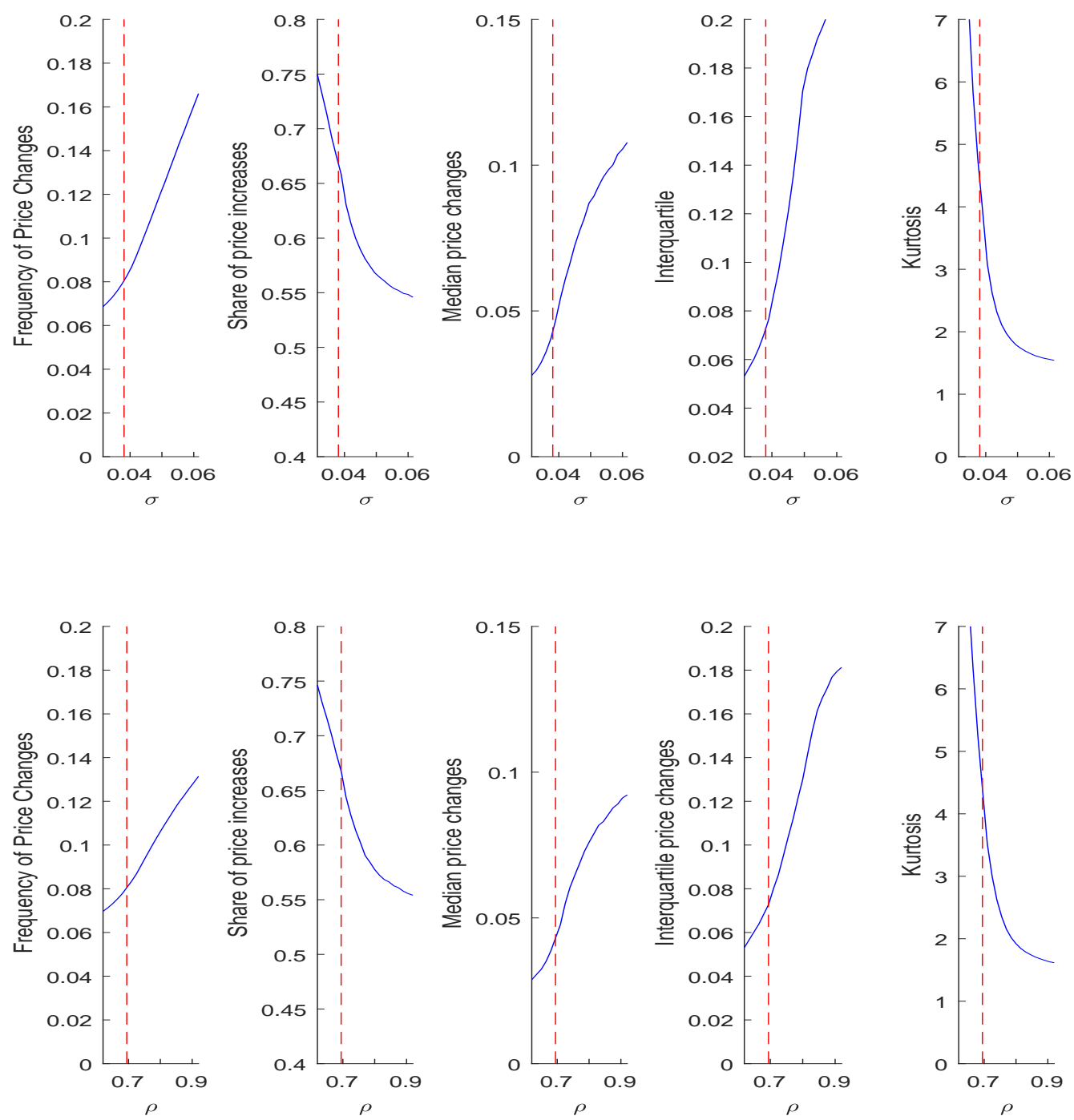

Note: Moments are simulated moments obtained from our model for a range of values of $\sigma_{\epsilon}$ (first row) and of $\rho$ (second row). We assume that other parameters are fixed to a baseline value $(\lambda=0.050, \mu=0.037, \sigma=0.038$, $\rho=0.69)$. The simulated model is a two-sector model $(K=2)$, featuring one small sector and one large sector. We run large simulations of the model under various parametrizations: each parameter in the small sector varies in turn on a grid, away from a baseline parameter value. The parameters of the larger sector are left unchanged across simulations. 
Figure 5: Distribution of estimated parameters across products
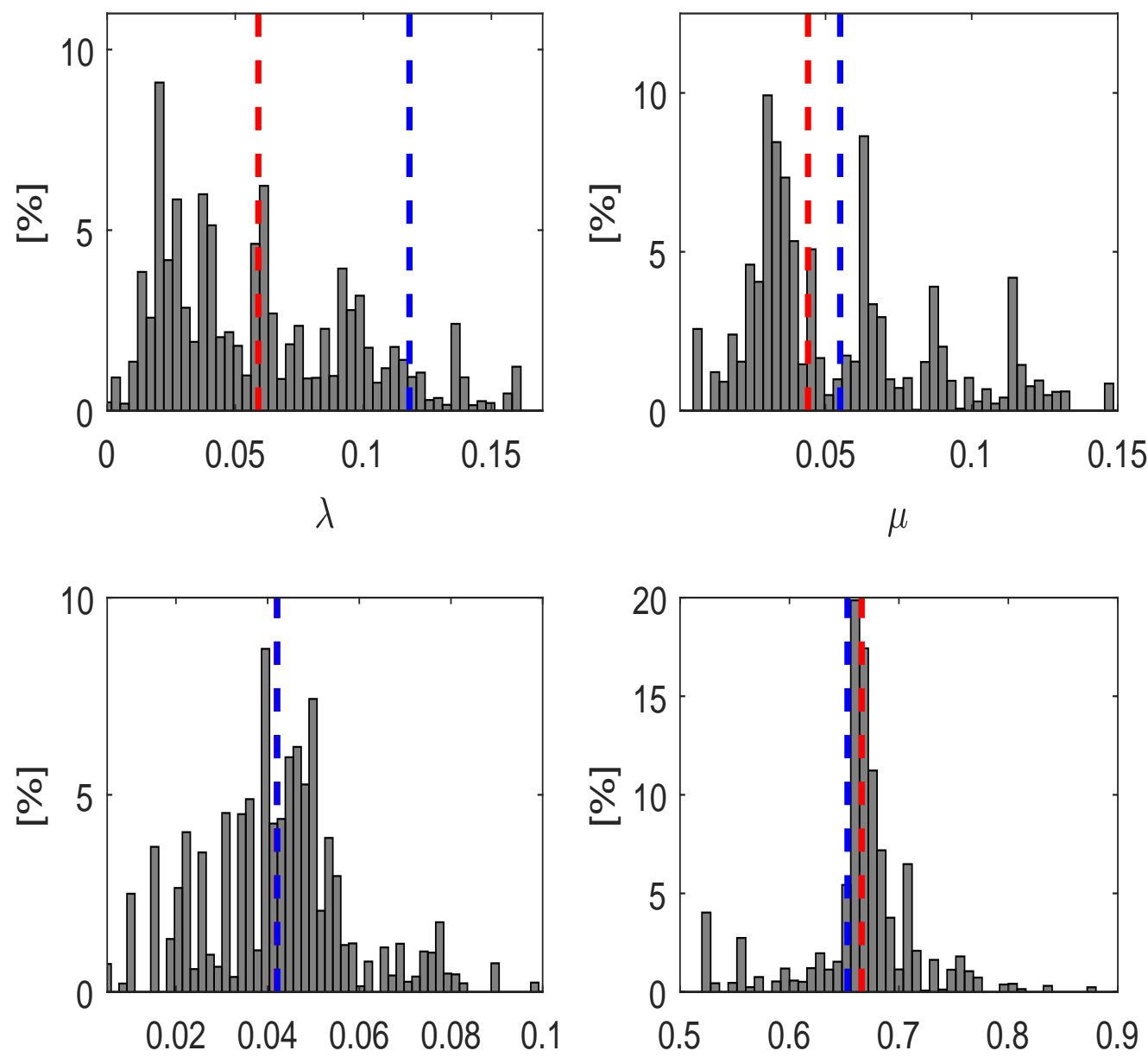

Note: The different histograms plot the distribution of each parameter estimated for all available CPI product categories. We have excluded energy products in the distribution of $\lambda$. Blue dashed line reports the average value of the distribution whereas the red dashed line reports the median of the distribution. The distribution and average and median parameters are all weighted using CPI weights. 
Figure 6: Cross product differences in the frequency of price changes and estimated parameters
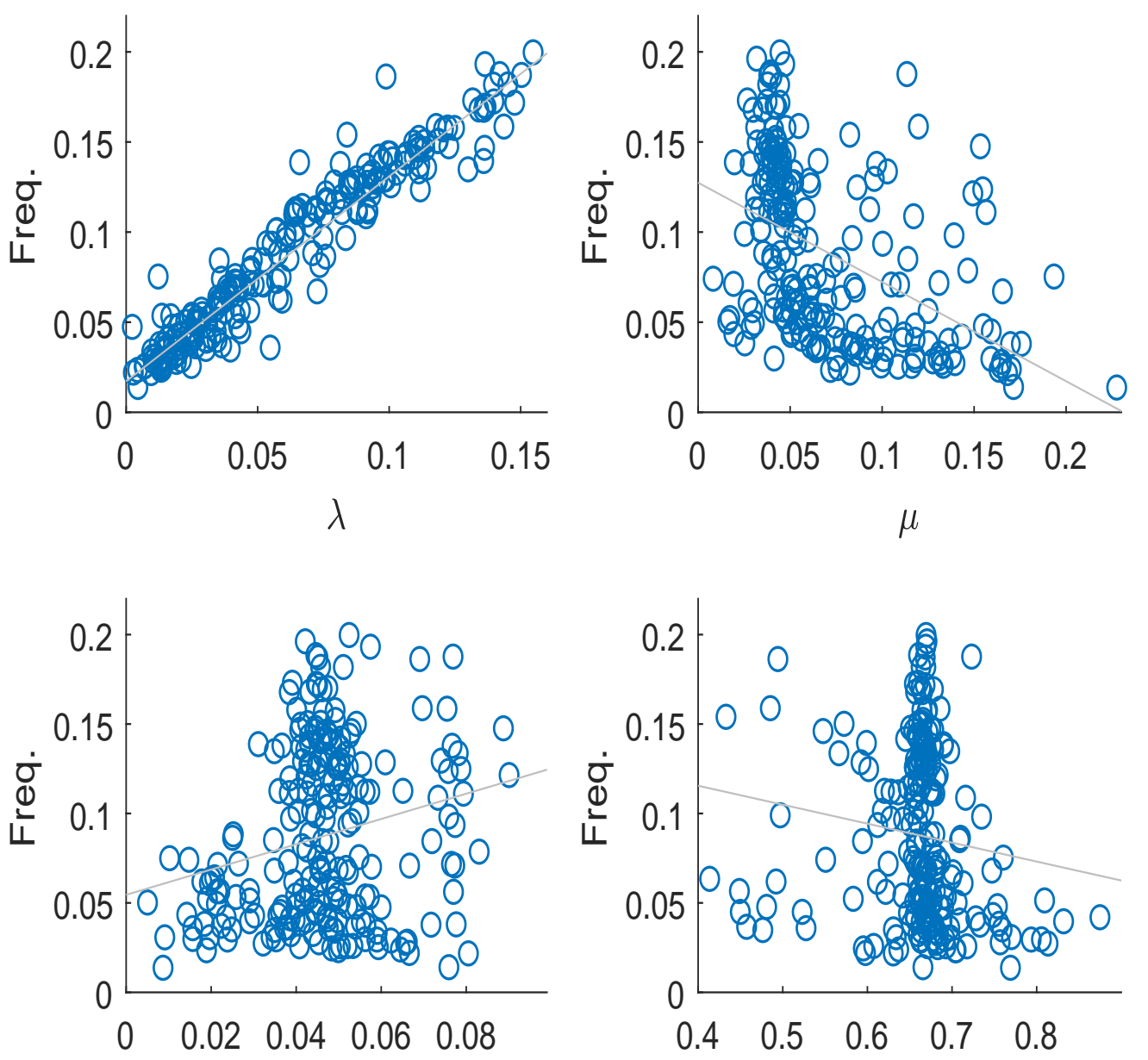

Note: Each point in the scatter plot is one of the 227 products, with values on the $\mathrm{x}$-axis indicating the value of the estimated parameter of interest for that product, and values on the $y$-axis reporting the value of the moment in that sector. The scatter plot is truncated (sectors with frequencies larger than 25 percent are not plotted) 
Figure 7: Cross product differences in the share of price increases and estimated parameters
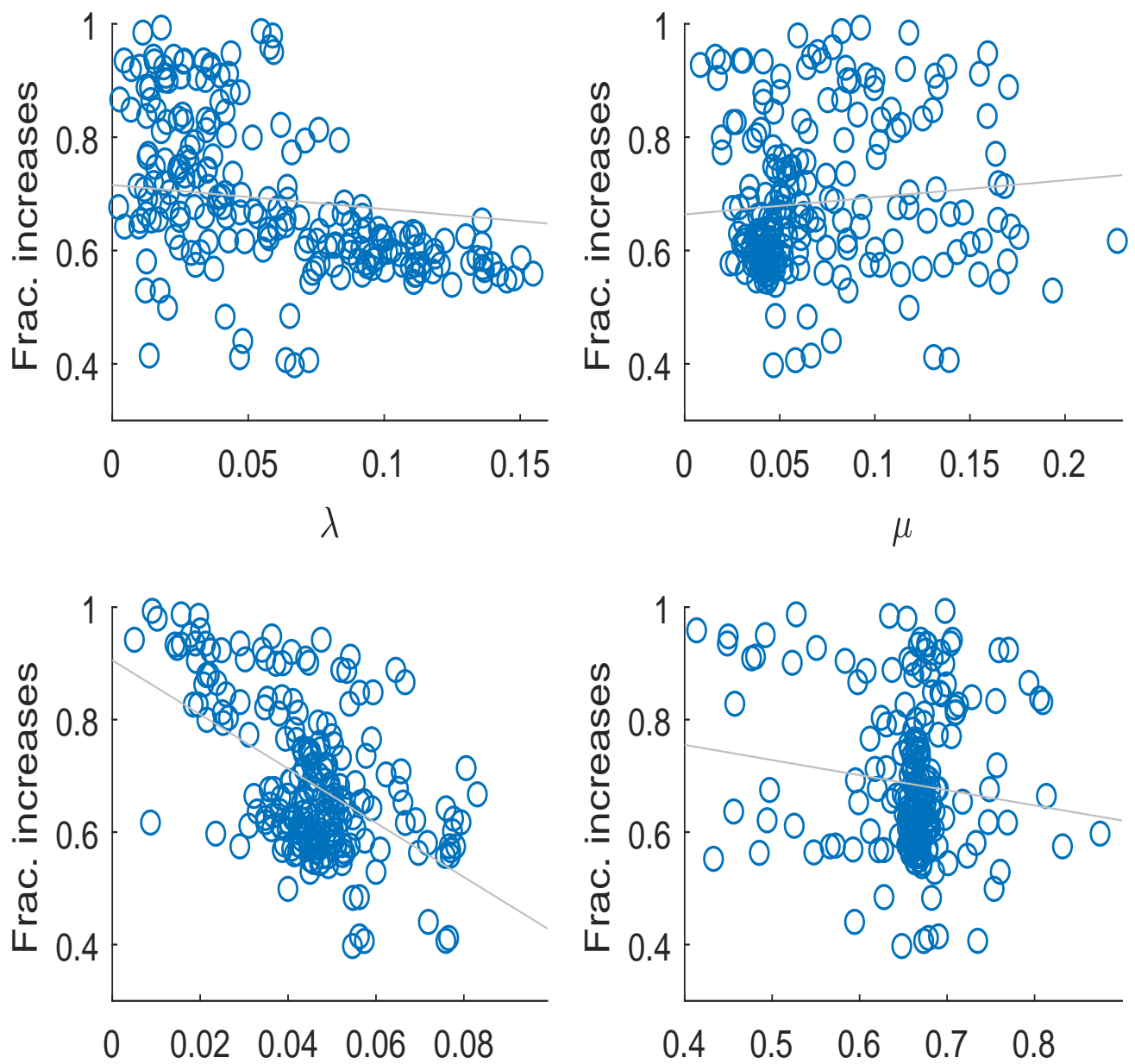

Note: Each point in the scatter plot is one of the 227 products, with values on the $\mathrm{x}$-axis indicating the value of the estimated parameter of interest for that product, and values on the $y$-axis reporting the value of the moment in that sector. 
Figure 8: Cross product differences in the median size of price changes and estimated parameters
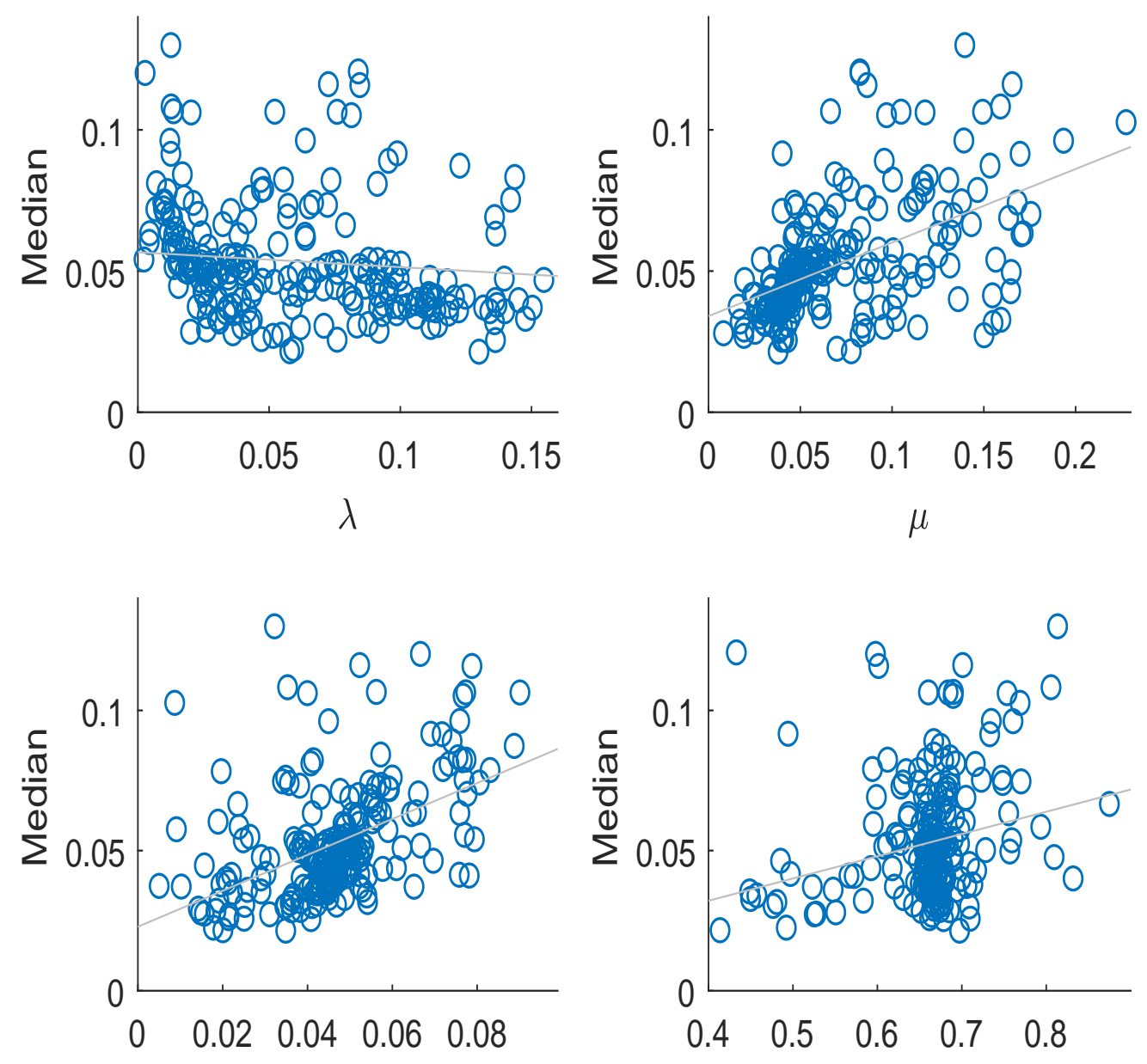

Note: Each point in the scatter plot is one of the 227 products, with values on the $\mathrm{x}$-axis indicating the value of the estimated parameter of interest for that product, and values on the $y$-axis reporting the value of the moment in that sector. 
Figure 9: Cross product differences in the interquartile size of price changes and estimated parameters
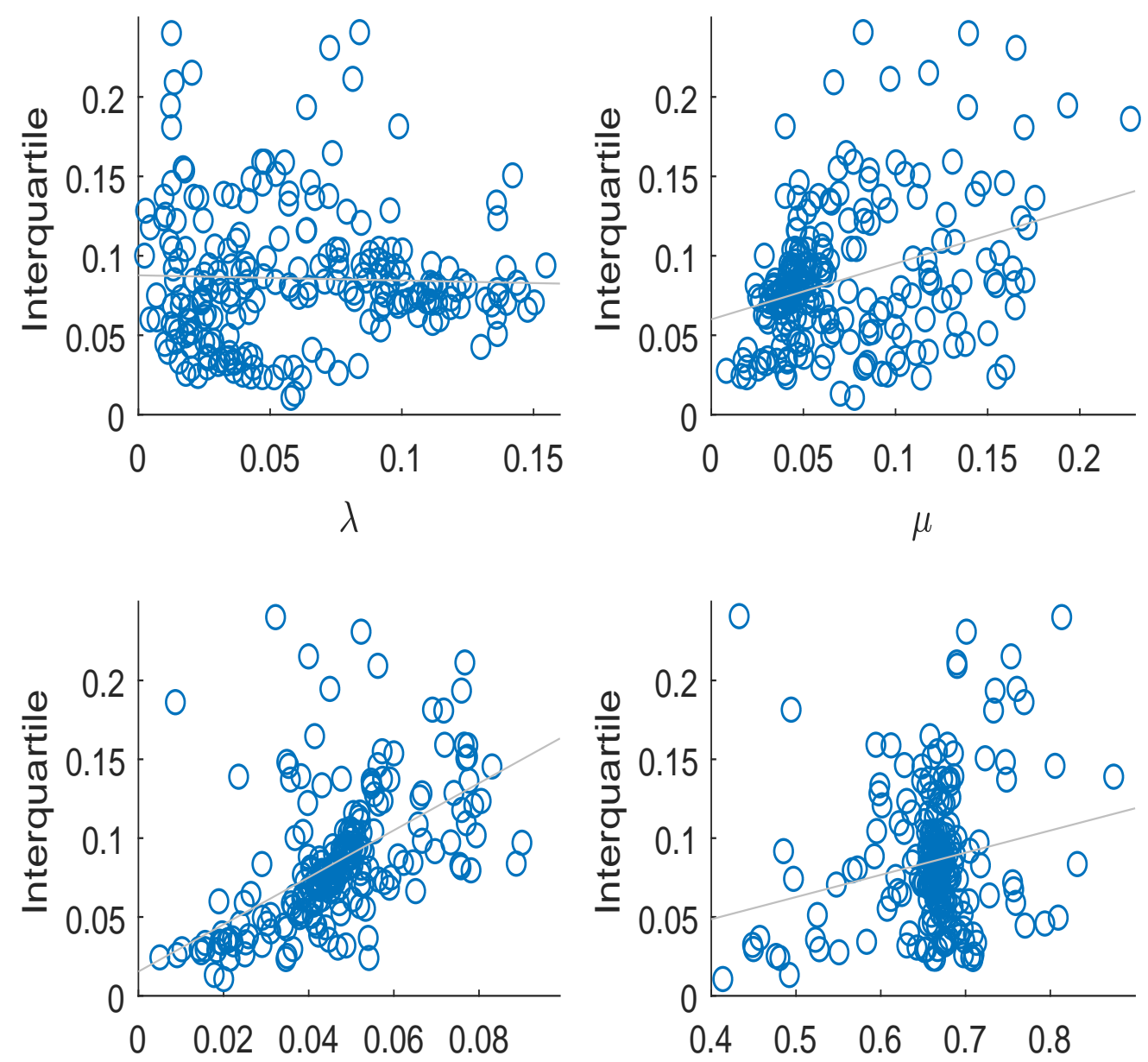

Note: Each point in the scatter plot is one of the 227 products, with values on the $\mathrm{x}$-axis indicating the value of the estimated parameter of interest for that product, and values on the y-axis reporting the value of the difference between the third quartile of the distribution of price changes and the first quartile of this distribution (for each sector). 
Figure 10: Cross product differences in the kurtosis of price changes and estimated parameters
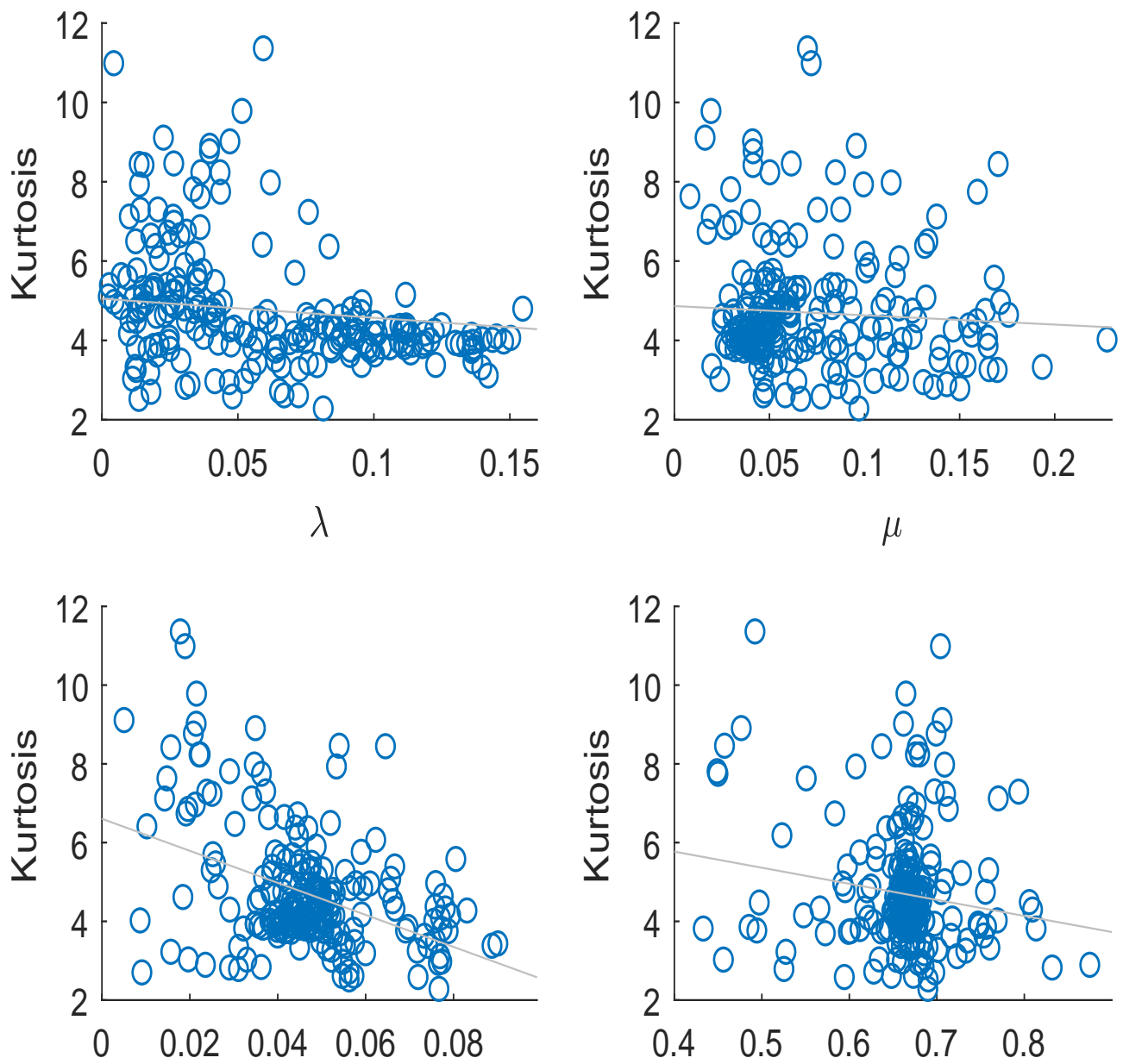

Note: Each point in the scatter plot is one of the 227 products, with values on the $\mathrm{x}$-axis indicating the value of the estimated parameter of interest for that product, and values on the $y$-axis reporting the value of the kurtosis of the distribution of price changes (for each sector). 
Figure 11: Impulse Response Function to a Monetary Shock - Variable Menu-Cost versus Calvo and Fixed Menu Cost

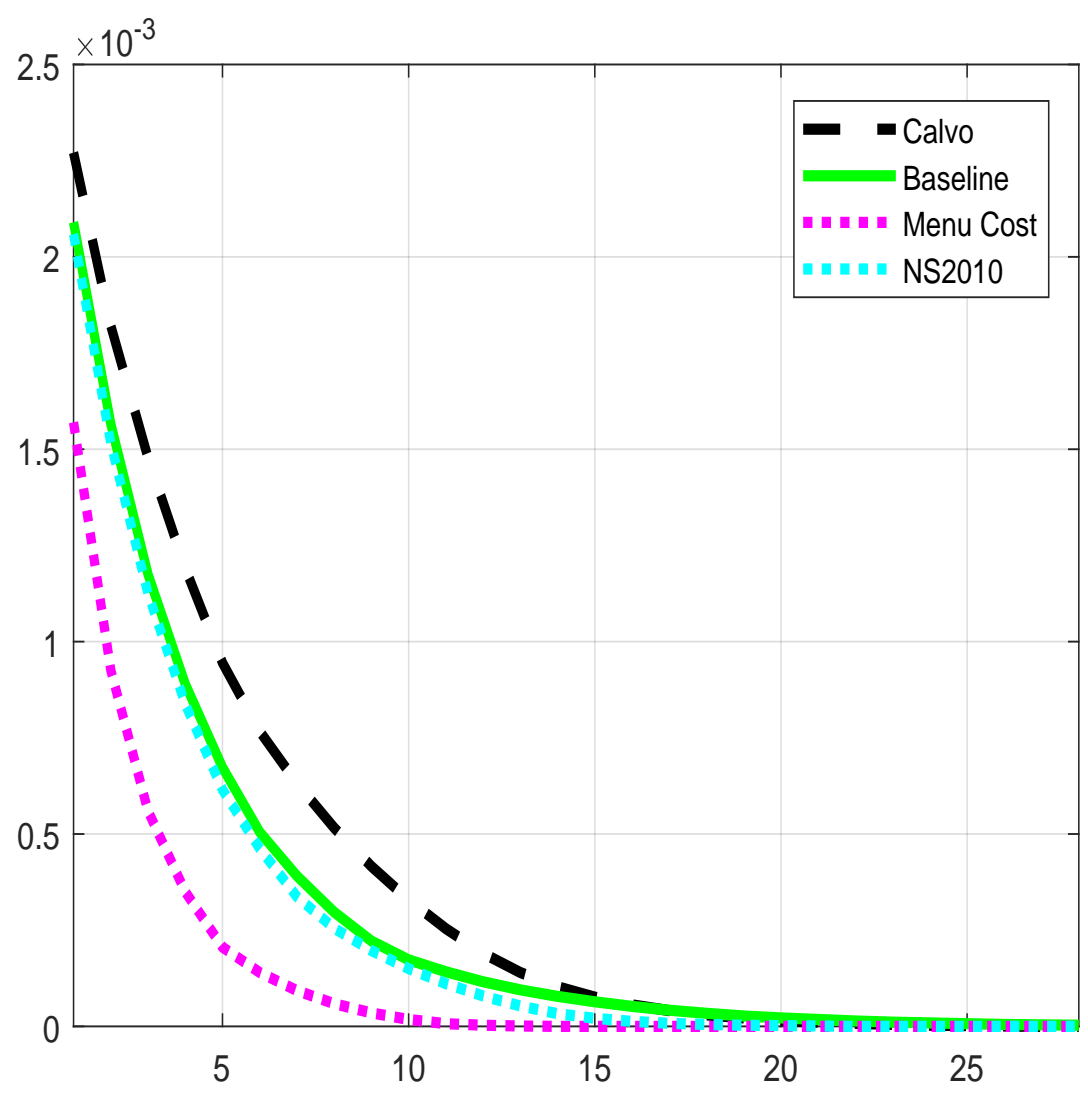

Note: We estimate a Calvo model (where all price changes are due to the low menu cost state), and a Menu Cost model (where all price changes are due to the high menu cost state). Using obtained estimated parameters, we simulate a monetary policy shock of one standard deviation of inflation. Using the Gamma function and estimated parameters of our one-sector models for France, we are able to calculate the aggregate response of output to this shock. The green line is the IRF corresponding to the French model where we estimate a one sector model fitting FR median moments of the data (with $s_{m}=0$ ). The pink dashed line is the IRF corresponding to a standard menu cost model (Golosov and Lucas (2007)) estimated on FR data. The black dashed line is the IRF corresponding to a standard Calvo model estimated on FR data. The blue line is the IRF corresponding to the Nakamura and Steinsson CalvoPlus model estimated on FR data. 
Figure 12: Impulse Response Function to a Monetary Shock - One versus Multisector Model $s_{m}=0.0$

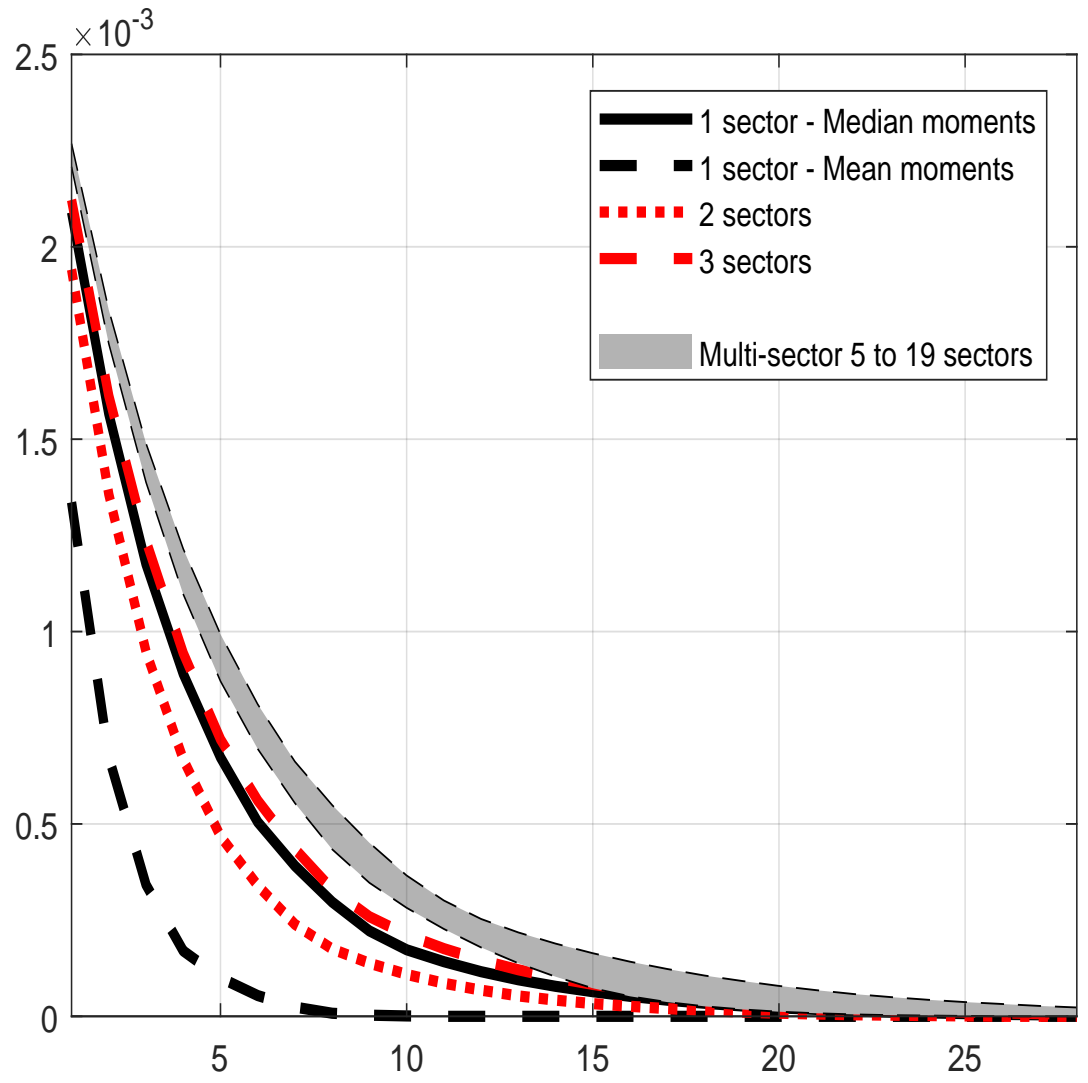

Note: In the model where the share of intermediate inputs is set to zero, we simulate a monetary policy shock of one standard deviation of inflation $(0.3 \%)$. Using the function $\Gamma$, and estimated parameters of our models, we are able to calculate the aggregate response of output to this shock. We consider here different cases where we use different sets of parameter estimates. The dark solid line is the IRF corresponding to the model where we estimate a one sector model fitting median moments of the data, the dark dashed line is the IRF corresponding to the model where we estimate a one sector model fitting the average moments of the data, the red dotted line is the IRF corresponding to the two-sector model (energy and core sectors), the red dashed line is the IRF corresponding to the three-sector model (non-energy goods, energy, services) and the red solid line the IRF corresponding to the four-sector model (food, manuf. goods, energy, services), the shaded area plots all IRFs obtained from multi-sector models where sectors group products according to the value of $\lambda$, we report IRF for models considering from 5 to 19 different sectors. 
Figure 13: Impulse Response Function to a Monetary Shock - France versus US - $s_{m}=0.0$

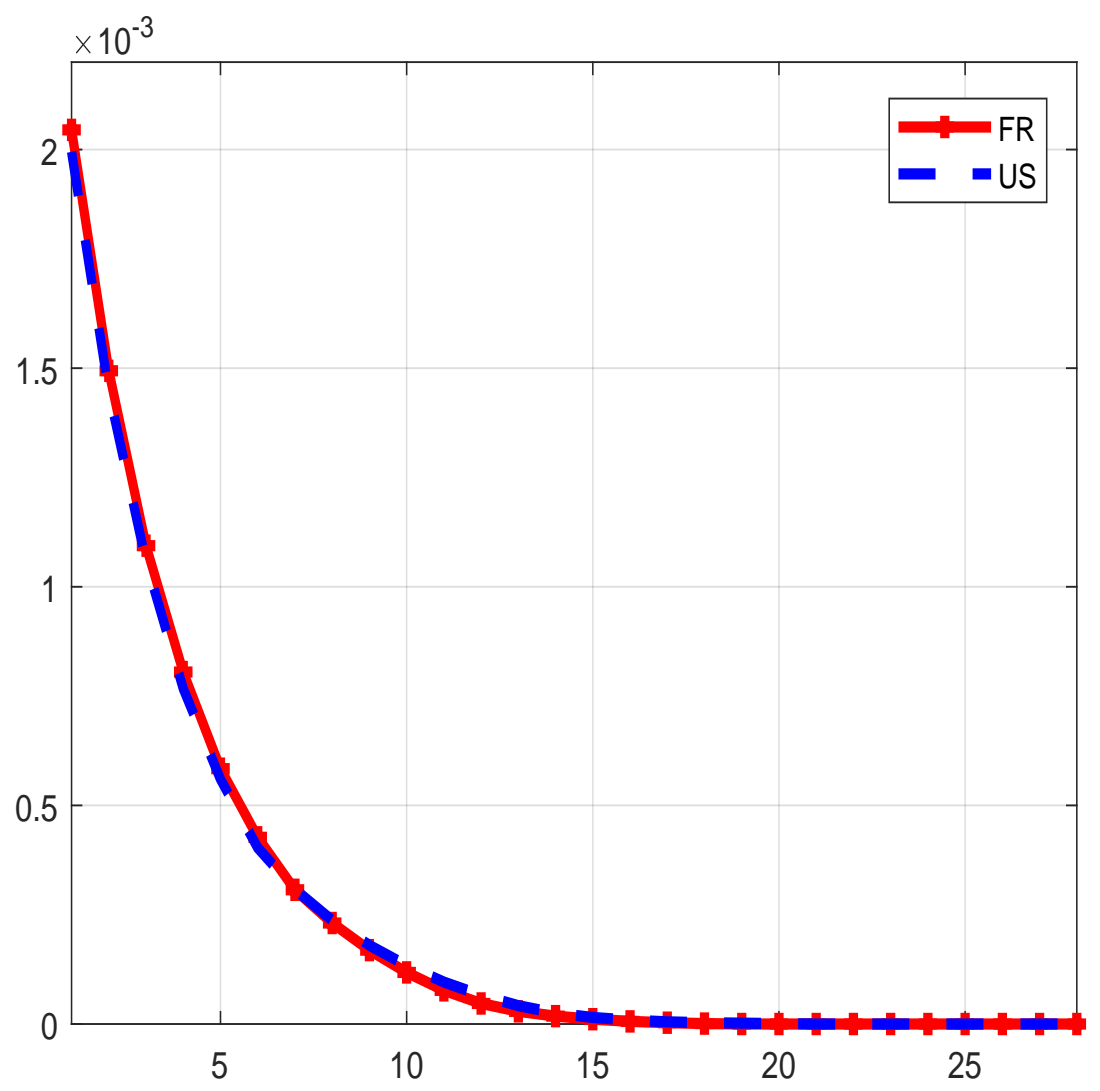

Note: In the model where the share of intermediate inputs is set to 0 , we simulate a monetary policy shock of one standard deviation of inflation. Using the function $\Gamma$, and estimated parameters of our models, we are able to calculate the aggregate response of output to this shock. We consider here different cases where we use different sets of parameter estimates. 


\section{Appendix}

\section{I) Model with Intermediate Inputs}

Production function becomes:

$$
Y_{i, k, t}=A_{i, k, t} L_{i, k, t}^{s_{m}} M_{i, k, t}^{\left(1-s_{m}\right)}
$$

$s_{m}:$ share of intermediate inputs

Index of intermediate input

$$
M_{i, k, t}=\left[\int_{0}^{1} m_{i, k, t}(j)^{\frac{1-\theta}{\theta}} d j\right]^{\frac{\theta}{1-\theta}}
$$

where $m_{i, k, t}(j)$ is intermediate input produced by firm $\mathrm{j}$ and used by firm i 
Table A: Share of intermediate inputs in production by aggregate sector - France - average 1994-2014

Sector

Code

Share of

$\%$ of overall

intermediate inputs

production

Overall

Manufacture of food products, beverages and tobacco

$\mathrm{CA}$

0.52

Manufacture of textiles, wearing apparels, leather

$\mathrm{CB}$

0.71

0.09

and related products

Manufacture of wood, paper and paper products

$\mathrm{CC}$

0.72

0.02

Manufacture of chemicals and chemical products

$\mathrm{CE}$

0.67

0.03

Manufacture of pharmaceutical products

$\mathrm{CF}$

0.75

0.04

Manufacture of rubber and plastic products

CG

0.49

0.01

Manufacture of fabricated metal products

$\mathrm{CH}$

0.63

0.03

except machinery and equipment

Manufacture of computer, electronic and optical products

CI

0.67

0.05

Manufacture of electrical equipment

CJ

0.59

0.02

Manufacture of machinery and equipment nec

CK

0.66

0.01

Manufacture of transport equipment

CL

0.67

0.02

Other manufacturing and repairing

$\mathrm{CM}$

0.79

0.06

Wholesale and retail trade;

GZ

0.57

0.04

repair of motor vehicles and motorcycles

Accommodation and food service activities

IZ

0.47

0.21

Telecommunications

$\mathrm{JB}$

0.45

0.05

Information

$\mathrm{JC}$

0.48

0.03

Financial and insurance activities

$\mathrm{KZ}$

0.34

0.03

Real estate activities

LZ

0.61

0.10

0.15

Note: The share of intermediate inputs is calculated using input-output tables provided by Insee national accounts over the period 1994-2014. The share of intermediate inputs is calculated as the share between intermediate inputs and production in a given sector whereas \% of overall production is calculated as the share of a given sector in overall production of all sectors considered in this table. 
Table B: Actual and Simulated Moments from the Estimated Models

\begin{tabular}{lccccc}
\hline & & & & & \\
& Freq. & Share of & \multicolumn{3}{c}{ Size of price changes } \\
& changes & increases & $\mathrm{p} 25$ & $\mathrm{p} 50$ & $\mathrm{p} 75$ \\
& & & & & \\
\hline & & & & & \\
France & & & & & \\
Data & 0.084 & 0.674 & 0.026 & 0.045 & 0.080 \\
Model $s_{m}=0.0$ & 0.084 & 0.624 & 0.019 & 0.050 & 0.079 \\
Model $s_{m}=0.7$ & 0.080 & 0.602 & 0.019 & 0.041 & 0.094 \\
& & & & & \\
US & & & & & \\
Data & 0.092 & 0.689 & 0.038 & 0.080 & 0.155 \\
Model $s_{m}=0.0$ & 0.088 & 0.596 & 0.031 & 0.087 & 0.135 \\
Model $s_{m}=0.7$ & 0.097 & 0.571 & 0.029 & 0.072 & 0.185 \\
& & & & & \\
\hline
\end{tabular}

Note: Calculations made on the French CPI micro data set over the period 1994-2014 (25 million of monthly price quotes). Price rigidity moments are first calculated at the product level and we then compute the weighted (using French CPI weights) median of those product-specific moments. Standard deviation of moments are calculated using 100 bootstrap simulations. Moments generated by the models at estimated values are also reported for cases where $s_{m}=0$ or $s_{m}=0.7$ 
Table C: Actual and Simulated Moments from the Estimated Models

\begin{tabular}{lccccc}
\hline & $\begin{array}{c}\text { Freq. } \\
\text { changes }\end{array}$ & $\begin{array}{c}\text { Share of } \\
\text { increases }\end{array}$ & \multicolumn{3}{c}{ Size of price changes } \\
& & & & & \\
& & & & \\
& & & & & \\
interquartile & kurtosis \\
Data & 0.084 & 0.674 & 0.044 & 0.070 & 4.462 \\
& & & & & \\
Menu Cost & 0.082 & 0.699 & 0.040 & 0.078 & 1.899 \\
Baseline & 0.081 & 0.668 & 0.041 & 0.067 & 4.400 \\
NS & 0.085 & 0.652 & 0.038 & 0.080 & 4.370 \\
Calvo & 0.084 & 0.597 & 0.037 & 0.074 & 3.182 \\
& & & & & \\
\hline
\end{tabular}

Note: Calculations made on the French CPI micro data set over the period 1994-2014 (25 million of monthly price quotes). Price rigidity moments are first calculated at the product level and we then compute the weighted (using French CPI weights) median of those product-specific moments. Standard deviation of moments are calculated using 100 bootstrap simulations. Moments generated by the models at estimated values are reported for models where $s_{m}=0$. 
Figure A: Moments: Actual Data vs Simulated Data $-s_{m}=0.0$
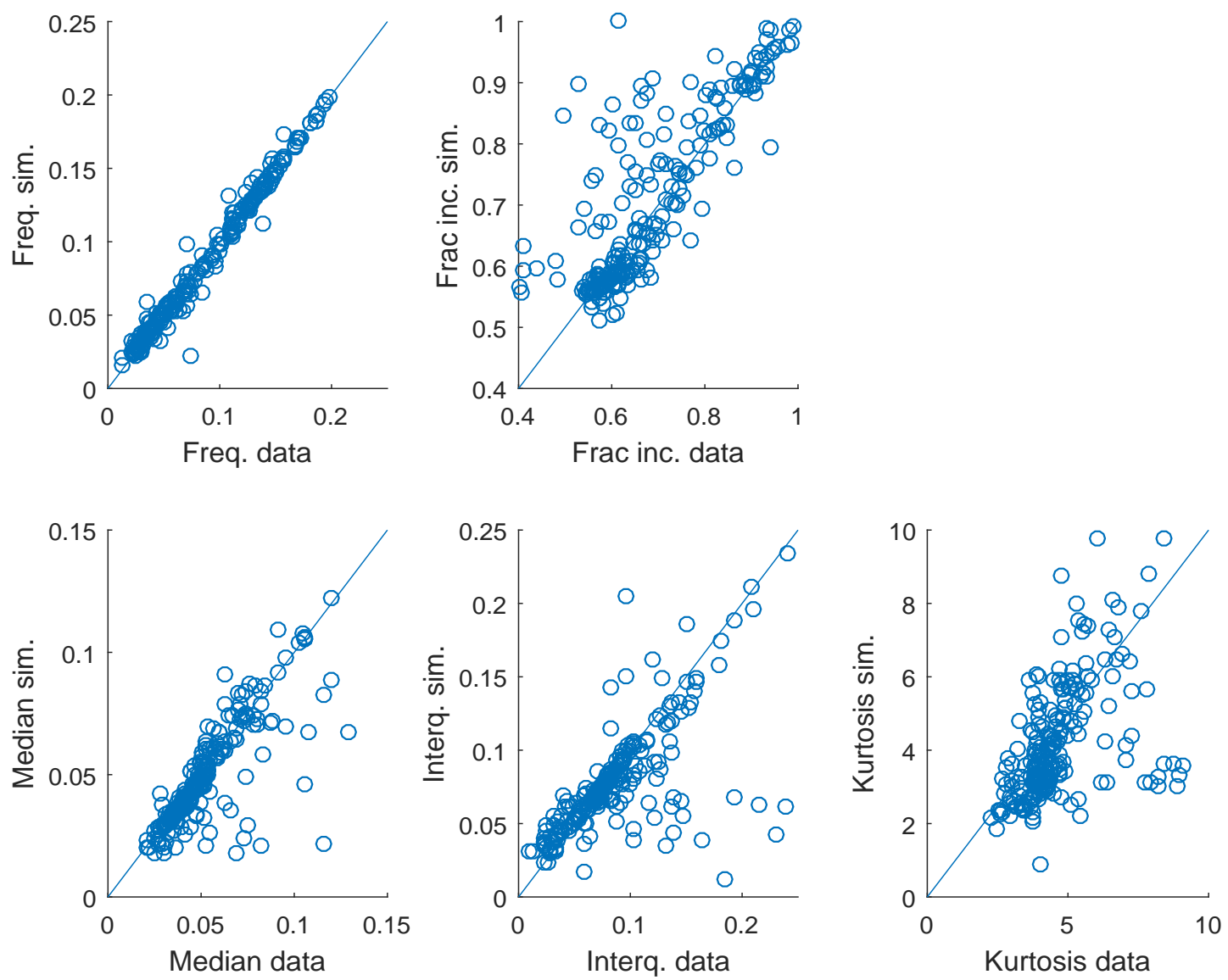

Note: Each point in the scatter plot is one of the 227 products, with values on the $\mathrm{x}$-axis reporting the value of the product-level moment measured in the data and values on the y-axis reporting the value of the product-level moment simulated by the model (using product-level parameter estimates). We have excluded energy products for the frequency. We here report scatter plots for moments used in our estimation procedure (i.e. the frequency of price changes, the fraction of price increases, the median size of price changes (in absolute values), the interquartile range and the kurtosis of the price change distribution. 
Figure B: Moments: Actual Data vs Simulated Data $-s_{m}=0.7$
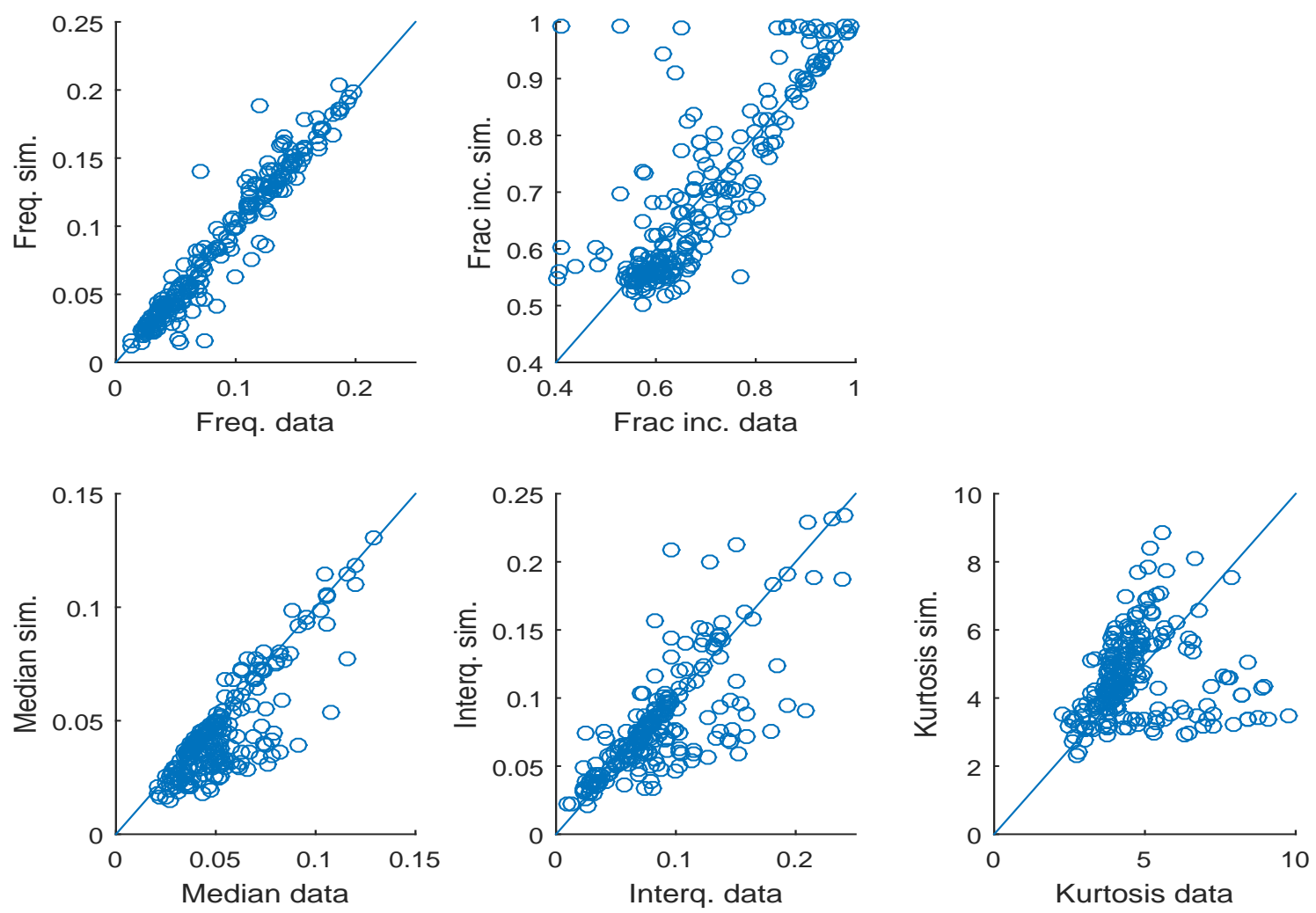

Note: Each point in the scatter plot is one of the 227 products, with values on the $\mathrm{x}$-axis reporting the value of the product-level moment measured in the data and values on the y-axis reporting the value of the product-level moment simulated by the model (using product-level parameter estimates). We have excluded energy products for the frequency. We here report scatter plots for moments used in our estimation procedure (i.e. the frequency of price changes, the fraction of price increases, the median size of price changes (in absolute values), the interquartile range and the kurtosis of the price change distribution. 


\section{II) Comparison with Alvarez, Le Bihan, and Lippi (2016)}

Alvarez, Le Bihan, and Lippi (2016) show that in a menu-cost model with random opportunity of free price change and assuming multiproduct firms, the cumulated output effect of a small monetary policy shock is a function of the kurtosis of non-zero price changes and of the frequency of price changes. Assuming an homogenous economy, and using the average moments to calibrate such an economy, the output response is shown to be proportional to $R \equiv K u r / F r e q$, where $\overline{K u r}$ and $\overline{F r e q}$ are the average kurtosis and frequency of the economy. Assuming an economy, with heterogeneous sectors, the cumulated output response is $R^{\text {het }} \equiv \sum_{k=1}^{K} w_{k} K u r_{k} / F_{r e q}$, where $w_{k}$ Kur $_{k}$ Freq $_{k}$ are CPI weights, kurtosis of price changes, and frequency of price changes in sector $k$ (see Appendix E in Alvarez, Le Bihan, and Lippi (2016)). Our set-up differs from Alvarez, Le Bihan, and Lippi (2016) since we do not have multiproduct firms, we allow for positive inflation rate and have freely estimated $\mathrm{AR}(1)$ shock for costs rather than Brownian motions, and moreover, we work with discrete time and approximate solutions rather than analytical solutions derived under continuous time. To compare our results with those provided by the analytical results of Alvarez, Le Bihan, and Lippi (2016), we calculate the ratio of kurtosis over frequency, using our micro data and considering different level of aggregation (results are available in Table $\mathrm{D}$ in Appendix). Based on the sample of our 227 products, using productlevel weights, frequencies and kurtosis we find an amplification factor $R^{\text {het }} / R$ of 2.35 . This amplification factor is smaller but not too far from the range of amplification factors we obtain in our baseline model 26

\footnotetext{
${ }^{26}$ One reason that can explain the discrepancy is we allow for cross-sector heterogeneity in the persistence of shocks, while all processes are assumed to follow a random walk in Alvarez, Le Bihan, and Lippi (2016)
} 
Table D: Amplification of real effects of monetary policy - Comparison with the "sufficient statistic approach" of Alvarez, Le Bihan, and Lippi (2016)

\section{Kurtosis Freq. Kur/Freq Amplification \\ Factor}

$\begin{array}{lcccc}\text { One sector - mean } & 5.28 & 0.137 & 38.59 & 1 \\ \text { One sector - median } & 4.46 & 0.084 & 53.28 & 1.38 \\ 5 \text { sectors - sector median } & - & - & 72.73 & 1.88 \\ \text { Fully heterogeneous model } & - & - & 90.74 & 2.35\end{array}$

Note: The table reports the ratio of kurtosis on frequency of price changes using different weighted schemes. First line, we compute the weighted average kurtosis and the weighted average frequency of price changes and calculate the simple ratio between the two aggregate statistics. Second line we are using weighted median of moments calculated over all products and calculate the ratio. Third line we are first calculating the ratio between median kurtosis and median frequency for the 5 aggregate products and then we compute the weighted average ratio. Fourth line, we are calculating the ratio kurtosis on frequency for all products and then we calculate the average weighted ratio. The last column reports the ratio between $\mathrm{R}$ obtained in different scenarios (lines 2 to 4 ) and the $\mathrm{R}$ obtained for the scenario with one sector - average moments (line 1). 
Figure C: Impulse Response Function to a Monetary Shock $-s_{m}=0.7$

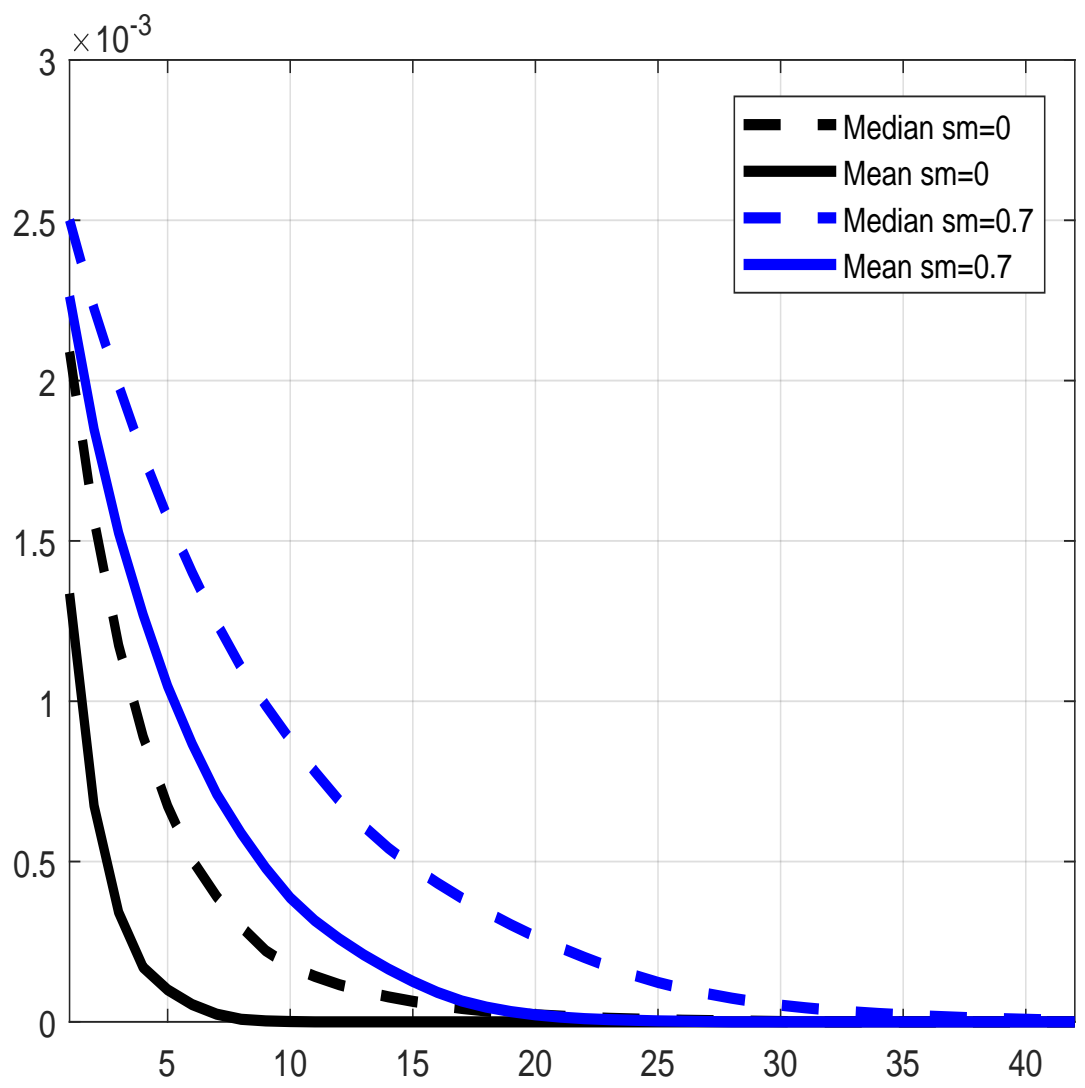

Note: In the model where the share of intermediate inputs is set to 0.7 , we simulate a monetary policy shock of $1 \%$. Using the function $\Gamma$, and estimated parameters of our models, we are able to calculate the aggregate response of output to this shock. We consider here different cases where we use different sets of parameter estimates. The dark dashed line is the IRF corresponding to the model where we estimate a one sector model fitting median moments of the data with $s_{m}=0$, the blue dashed line is the IRF corresponding to the model where we estimate a one sector model fitting the median moments of the data but with $s_{m}=0.7$; the black solid line is the IRF corresponding to the model where we estimate a one sector model fitting the average moments of the data with $s_{m}=0$, the dark dashed line is the IRF corresponding to the model where we estimate a one sector model fitting the average moments with $s_{m}=0.7$. 
Figure D: Impulse Response Function - Sorting sectors according to $\lambda, \mu$ or $\sigma$

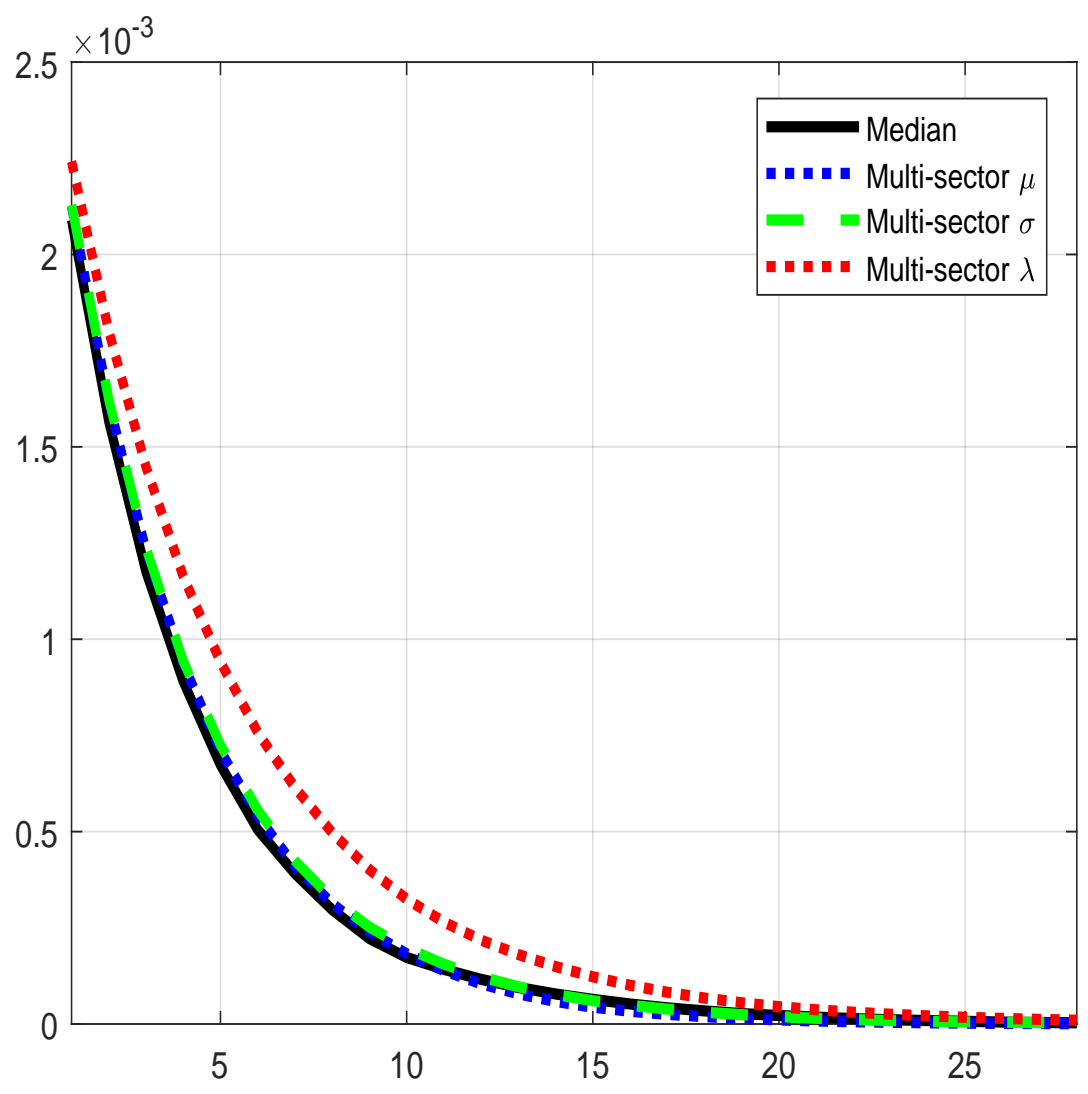

Note: In the model where the share of intermediate inputs is set to zero, we simulate a monetary policy shock of one standard deviation of inflation $(0.3 \%)$. Using the function $\Gamma$, and estimated parameters of our models, we are able to calculate the aggregate response of output to this shock. We consider here different cases where we use different sets of parameter estimates. The red dotted line plots the average IRF obtained from multi-sector models where sectors mean groups of products according to the value of $\lambda$, the blue dotted is similar but groups of products are defined according to product-values of $\mu$ whereas the green dashed line is the average IRF for models where sectors are defined according to product-values of $\sigma$. Average IRF are calculated for models considering from 5 to 19 different sectors. We also plot the IRF obtained with a single sector estimated using median aggregate moments (solid black line).). 
Table E: Cumulated Real Output Effect of a Monetary Shock - Single versus Multi-Sector Model $-s_{m}=0.7$

\section{Real effects Amplification}

Single sector (Mean moments)

Single sector (Median moments)

Multi-sector models (Mean moments)

4-sector model (Food Manuf - Services - Energy)
0.0124

0.0220

0.0201

\section{1}

1.78

1.63

$\begin{array}{lrr}\text { Multi-sector models (product-level parameters) }-5 \text { to } 13 \text { sectors } & \\ \lambda & {[0.0260 ; 0.0304]} & {[2.10 ; 2.46]} \\ \mu & {[0.0177 ; 0.0225]} & {[1.44 ; 1.82]} \\ \sigma & {[0.0174 ; 0.0258]} & {[1.41 ; 2.09]}\end{array}$

Note: We report in this table the cumulated real monetary effect (calculated after 50 months) of a one-standard deviation money shock $(0.3 \%)$ in different models. A first group of results (lines 1 and 2 ) report the results for our baseline model (menu cost with possibility of free price adjustment) estimated on aggregate weighted moments (mean and median). A second group of results reports the results of multi-sector models estimated on sectoral weighted moments (mean moments calculated for COICOP broad sectors). A last group of results uses parameters from our two-sector models estimated for our 227 products. We here report real effects for different grouping of products (from 5 to 19 groups of products). We first sort product parameters according to the estimated values of one given parameter $(\lambda, \mu$ or $\sigma)$. We then group products according to their position on the distribution of this given parameters. We then calculate for each group the median value of all parameters in this group. Finally, we estimate the real effects of monetary policy considering a multi-sector model made of these groups of products. We are reporting the minimum and the maximum values we obtain for models with 5 to 19 groups of products. Amplification factor is the ratio of line (1) to other lines. 
Figure E: Impulse Response Function - Sorting sectors according to $\lambda, \mu$ or $\sigma-s_{m}=0.7$

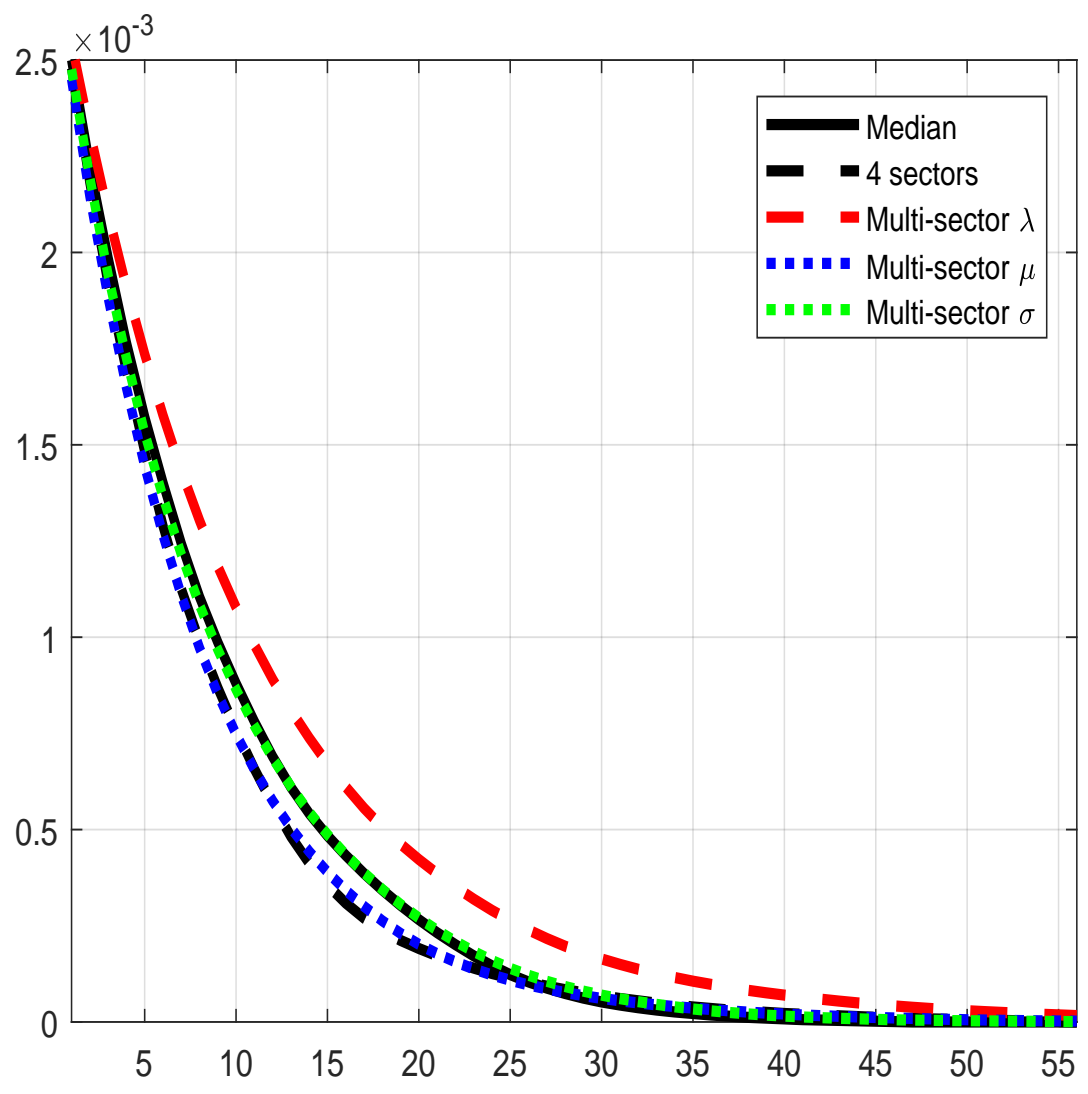

Note: In the model where the share of intermediate inputs is set to 0.7 , we simulate a monetary policy shock of one standard deviation of inflation $(0.3 \%)$. Using the function $\Gamma$, and estimated parameters of our models, we are able to calculate the aggregate response of output to this shock. We consider here different cases where we use different sets of parameter estimates. The red dotted line plots the average IRF obtained from multi-sector models where sectors mean groups of products according to the value of $\lambda$, the blue dotted is similar but groups of products are defined according to product-values of $\mu$ whereas the green dashed line is the average IRF for models where sectors are defined according to product-values of $\sigma$. Average IRF are calculated for models considering from 5 to 19 different sectors. We also plot the IRF obtained with a single sector estimated using median aggregate moments (solid black line) and with a four-sector model (energy, non-energy non-food goods, food and services).). 
Figure F: Impulse Response Function to a Monetary Shock - France versus US - $s_{m}=0.7$

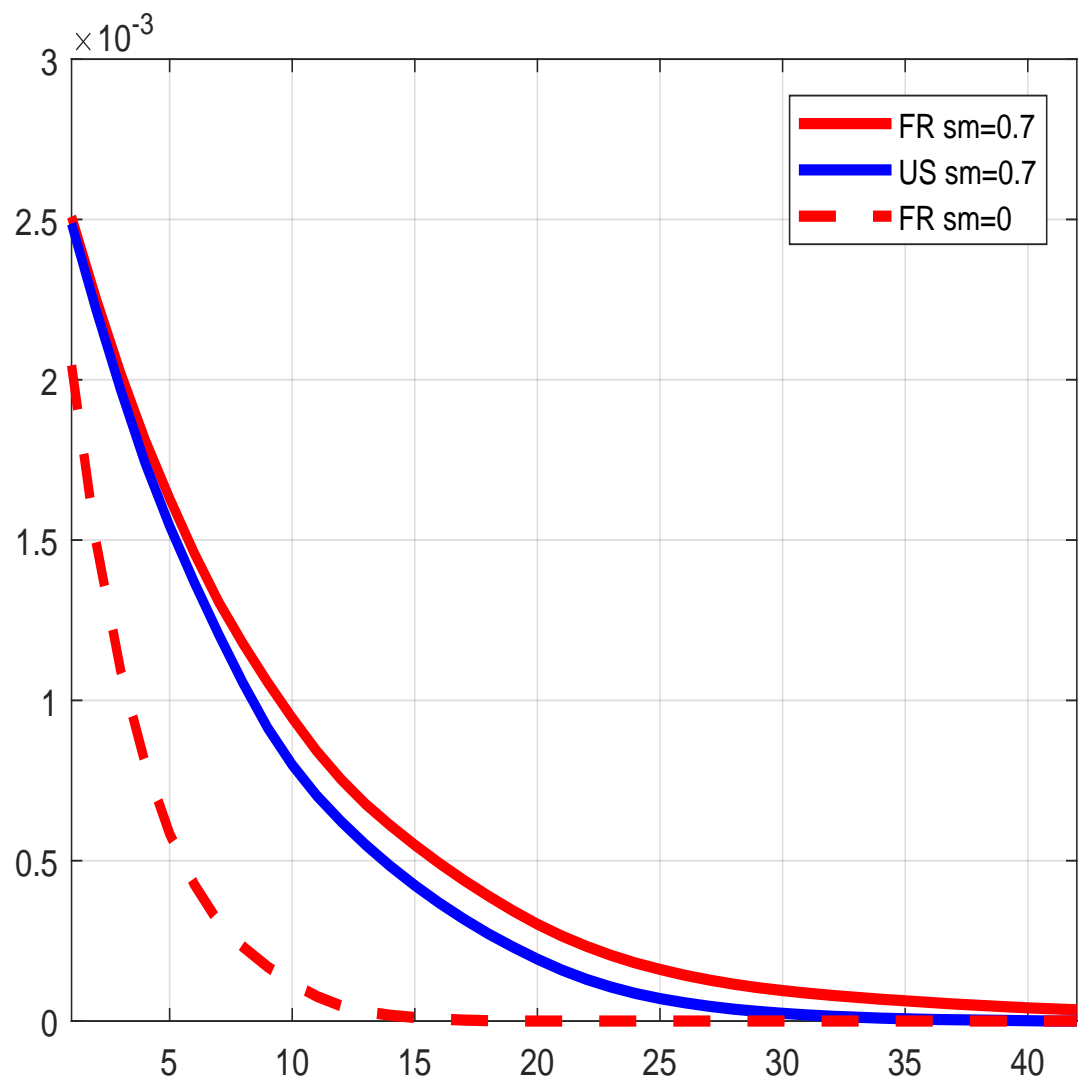

Note: We report in this table the cumulated real monetary effect (calculated after 50 months) of a one-standard deviation money shock $(0.3 \%)$ in single-sector models estimated using French or US data (the share of intermediate inputs is assumed to be 0.7). Red line reports the results for our baseline model (menu cost with possibility of free price adjustment) estimated on French aggregate median weighted moments (including first and third quartiles of the price change distribution). In dashed line, we have reported the French IRF obtained when $s_{m}=0$ whereas in solid line the IRF obtained when $s_{m}=0.7$. Blue line reports the results for our baseline model estimated on US aggregate median weighted moments (including first and third quartiles of the price change distribution) ( $s_{m}$ is here assumed to be 0.7 ). 